\title{
Advance in photonic crystal solar cells
}

\author{
Wei Liu ${ }^{a}$, Hailing Ma ${ }^{\text {b, }}$, Annika Walsh ${ }^{\mathrm{c}}$ \\ ${ }^{\text {a }}$ Business School, Qingdao University, Qingdao, 266100, China \\ ${ }^{\mathrm{b}}$ Institute of Mechanics, Chinese Academy of Sciences, Beijing, 100190, PR China \\ ${ }^{\mathrm{c}}$ University of Arizona, Tucson, AZ, 85721, USA
}

\section{A R T I C L E I N F O}

\section{Keywords:}

Photonic crystal

Solar cells

Silicon

\begin{abstract}
A B S T R A C T
Photonic crystals have been widely used in solar cells in recent years because of their unique optical properties such as photonic band gap and "slow photon" effect. The introduction of photonic crystals can adjust the propagation and distribution of photons in solar cells. Therefore, a full understanding of the optical properties of photonic crystals and the correct use of photonic crystals are the key to improve the photoelectric conversion efficiency. At present, photonic crystal structures are widely used in dye sensitized solar cell (DSSC) and quantum dots sensitized solar cell (QDSSC), but relatively few in the field of perovskite solar cell (PSC). In this paper, the applications of different types of photonic crystals in silicon solar cells and sensitized solar cells are summarized, and the possible problems are analyzed and commented. It is pointed out that although photonic crystals have many excellent optical control properties, it is difficult to meet the thickness requirements of PSC due to the limitations of preparation technology and structure of photonic crystals. At present, the photoelectric conversion efficiency of photonic crystal PSC is generally low. Therefore, develop new technology for preparing the large area and high quality ultra-thin photonic crystals, make a profound study of photonic crystal light control mechanism, design new structures, and explore new functions of photonic crystals will become the future development direction of photonic crystal solar cells.
\end{abstract}

\section{Introduction}

At present, the rapid development of economy leads to the rapid exponential growth of global consumption of fossil energy every year. Meanwhile, the dependence of economic development on energy also keeps increasing, and the phenomenon of energy shortage is increasingly prominent worldwide [1,6]. At present, people's energy consumption mainly depends on non-renewable fossil fuels such as coal, oil and natural gas. These fossil fuels are not only limited in supply, but also will inevitably cause serious environmental pollution in the process of exploitation and use. With the development and progress of society, due to the large use of conventional energy, especially fossil fuels, human living environment will continue to deteriorate, which will seriously affect human health. At the same time, the high-speed consumption of fossil fuels will one day run out. If there is no real alternative to fossil energy when fossil energy is exhausted, it will seriously hinder the sustainable development of the global economy and even seriously affect people's normal life. In order to alleviate the deteriorating environmental problems and energy crisis, protect the environment and reduce pollution, countries have focused on clean and renewable energy sources such as solar energy and wind energy, and are scrambling to find alternatives for fossil energy [2,6].

Among all the renewable energy sources concerned at present, solar energy, with its inexhaustible, inexhaustible, pollution-free, easily accessible and abundant sources, has been recognized as an extremely important way to solve the current energy crisis [3-6], and has attracted more and more researchers' attention. Solar energy can provide permanent clean energy for human beings, but solar energy can't be directly used. The most common form of conversion of solar energy is to convert solar energy into electric energy. At the same time, zero pollution and zero emissions in the process of converting solar energy into electric energy avoid the generation of harmful gases such as sulfur dioxide and carbon dioxide when using fossil fuels, thereby reducing environmental pollution and protecting the environment $[5,6]$. Therefore, the widespread use of solar cells can effectively solve the two major social problems that need to be solved urgently, namely, energy and environment.

Photonic crystal is a new concept put forward in 1980s [7]. Similar to potential modulation in semiconductors, photonic crystals can regulate the propagation and emission of photons, also known as

\footnotetext{
* Corresponding author.

E-mail address: hailingma@yeah.ne (H. Ma).
} 
photo-semiconductors [7]. The era of optical information has created new opportunities for the development of photonics technology. It has been praised as "the ten most important scientific advances" in the world by Science magazine for two consecutive years, and is predicted to be one of the six research hotspots in the future. Improving the performance of solar cells with photonic crystals has also attracted wide attention $[7,8]$.

\section{Photonic crystal}

Photonic crystals are microstructures formed by periodic arrangement of two or more dielectric materials with different dielectric constants in space [6]. When light propagates through a photonic crystal, the photons are also modulated by the structure in which the dielectric constants of the photonic crystals are periodically arranged. Bragg scattering occurs when light propagates in photonic crystals, resulting in band structure of photonic crystals. The band gap between two adjacent photonic band structures is called photonic bandgap (PBG) $[6,9,10]$. The characteristic of photonic bandgap is that photons in a certain direction can be prohibited from propagating in photonic crystals at a certain frequency or wavelength range $[6,10]$. The photonic forbidden band is usually divided into two kinds: the complete photonic forbidden band and the incomplete photonic forbidden band. Complete photonic band gap is an omni-directional photonic band gap, i.e. the propagation or polarization of photons in a specific frequency or wavelength range are prohibited in all directions of photonic crystals. Similarly, incomplete photonic band gap means that there exists photonic band gap only in a specific direction $[11,12]$. The photonic band gap of photonic crystals can be changed by changing the lattice parameters of photonic crystals and the dielectric constant of dielectric materials.

There are many similarities between the physical properties of photonic crystals and ordinary semiconductor crystals [6]. In semiconductor physics, there are many common concepts and methods to study semiconductor crystals, such as Brillouin region, dispersion relation, and Bloch wave, which can be used to study the optical properties of photonic crystals [6]. However, there are differences between the two kinds of crystals. The studies on semiconductor crystals focus on electrons. Electrons are fermions, and the propagation of electrons in semiconductor crystals must satisfy the Schrodinger equation. while the research object of photonic crystals is photons. Photons are bosons, and photons propagate in photonic crystals must satisfy Maxwell's equation [6]. Photonic crystals can be divided into one-dimensional, two-dimensional and three-dimensional photonic crystals according to different spatial periodic arrangements of materials with different dielectric constants [13,14] (Fig. 1).

One-dimensional photonic crystals are photonic crystals whose dielectric constants are periodically arranged in only one direction [6]. Generally, it consists of two or more dielectrics with different dielectric constants superimposed in one direction, and only a photonic band gap exists in the direction in which the thin layers of semiconductor material are stacked [6]. One-dimensional photonic crystals are simple in structure, low in preparation cost and high in optical accuracy, which makes them easier to produce and prepare $[6,15]$. Two-dimensional photonic crystals are photonic crystal materials with different dielectric constants arranged periodically in two directions, that is, they can restrict the propagation of photons in the photonic crystals in two directions [6]. Similarly, three-dimensional photonic crystals refer to crystal structures periodically arranged in three-dimensional space by dielectric materials with different dielectric constants, the photonic band gap can be formed in all directions to limit the propagation of photons [6]. The superior optical properties of three-dimensional photonic crystals make them have a broader application prospect compared with the first two kinds of photonic crystals. However, the structure of three-dimensional photonic crystals is too complex, which requires high fabrication technology and is not easy to be prepared [6].

In order to study the optical properties of photonic crystals with different structures, researchers have proposed many theoretical calculation methods for photonic crystals in recent years [6]. The more widely used methods for calculating photonic crystals are plane wave expansion [16], transmission matrix [17,18], finite-difference time-domain method [19], and scattering matrix method [20]. In terms of applications, the superior optical properties of photonic crystals make it applicable to more fields, such as high-performance mirrors, super-prismsand other optical devices, as well as photonic crystal fibers, photonic crystal waveguides, photonic crystal filters, etc. [19].

One-dimensional photonic crystals can be prepared by a variety of mature coating processes. The preparation processes of two- and threedimensional photonic crystals are discussed emphatically.

The preparation process of two-dimensional photonic crystal. Photonic crystals in microwave region can be prepared by means of dielectric strip stacking. However, it is difficult to prepare a photonic crystal in the visible light region or the infrared light region by this method. Since the behavior of photons in a photonic crystal is similar to the behavior of electrons in a semiconductor crystal, the advanced nanofabrication technology can be used to prepare photonic crystals in the visible region and the infrared region by referring to the mature semiconductor machining process. Such as electron beam etching, reactive ion beam etching and laser etching [21]. Wendt et al. [22] fabricated two-dimensional AlGaAs thin film photonic crystals on GaAs substrates by electron beam direct writing and reactive ion beam etching. The principle of this method is to define two-dimensional photonic crystal structure pattern on the electronic glue by the single point exposure technique written directly by the electron beam, then two-dimensional photonic crystal patterns are obtained by development technique, finally, the pattern is then transferred to the AlGaAs film by the reactive ion beam etching method. It was subsequently developed as the combination technology of multi-point exposure and reactive ion beam etching. Krauss et al. [23] used this technique to fabricate GaAs-based photonic crystals. The time required to use single point exposure is about $1 / 10$ of that of multi-point exposure, but it does not allow for exposure correction. Fnglund et al. [24] fabricated photonic crystal microcavities using the similar method in 2007. Chelnokov et al.

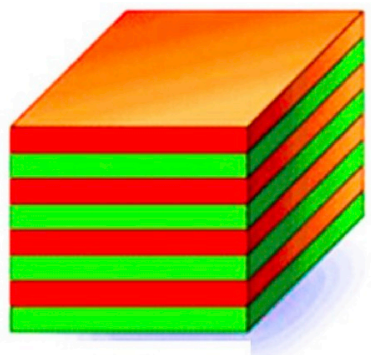

(a) $1 \mathrm{D}$

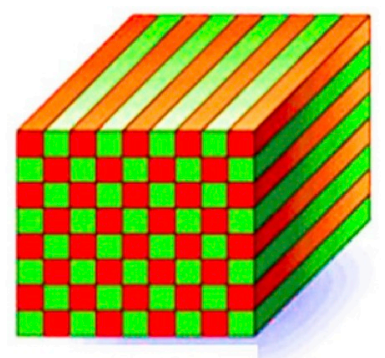

(b) $2 \mathrm{D}$

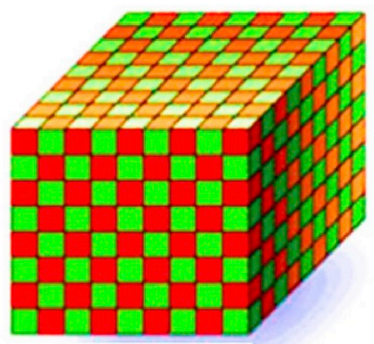

(c) $3 \mathrm{D}$

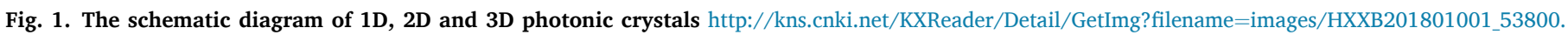

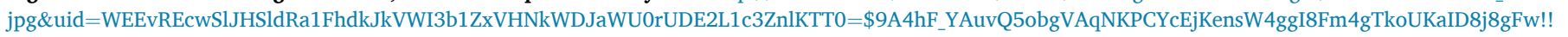


[25] used electrochemical methods to etch anodized aluminum to obtain two-dimensional photonic crystals with large aspect ratio periodic micropores. In addition to etching anodic alumina, two-dimensional photonic crystals can also be prepared by liquid etching method, but only two-dimensional photonic crystals with larger aperture can be prepared by liquid etching method. At present, important progress has been made in the preparation of two-dimensional photonic crystals, but still faces many key challenges, such as the control of the two-dimensional photonic crystal preparation error and the improvement of precision required for practical application of photonic crystals.

Because thin-film crystalline silicon (c-Si) solar cells have lighttrapping structures, light absorption within the semiconductor absorption layer can be enhanced, and material usage be reduced. Anastassios Mavrokefalos et al. [90] demonstrate that light absorption within the c-Si layer can be significantly enhanced through inverting a nanopyramid light-trapping scheme for c-Si thin films. The films are fabricated at wafer scale via a low-cost wet etching process. It is proved that a broadband enhancement in absorptance that approaches the Yablonovitch limit is achieved with minimal angle dependence. The results show that the achievable absorptivity of c-Si films with thicknesses less than $10 \mu \mathrm{m}$ is comparable to that of planar c-Si wafers with thicknesses greater than $300 \mu \mathrm{m}$, which is equivalent to an over 30 -fold reduction in material usage. These structures can not only significantly reduce the material and processing costs of solar cells, but also provide the high efficiency needed to enable viable c-Si thin film solar cells in the future.

Matthew S. Branham et al. [91] designed a 10-micron-thick crystalline silicon photovoltaic cell with a peak efficiency of $15.7 \%$. The designed two-dimensional inverted nanopyramid surface texture and rear metallic reflector light-trapping structure are the main features of the cell. It has been proven to have excellent anti-reflection and long-wavelength absorption capabilities. The cell is found to provide near lambert absorption in the $500-1100 \mathrm{~nm}$ spectrum, and the peak short-circuit current measured is $34.5 \mathrm{~mA} \mathrm{~cm}{ }^{2}$, which indicates substantial improvement over the previous equipment in this thickness range. The designed cell structure is shown in Fig. 2. The surface of the cell is patterned with a two-dimensional photonic crystal of inverted pyramids on a $700 \mathrm{~nm}$ pitch.

Sayak Bhattacharya et al. [92] demonstrate that thin-crystalline silicon (c-Si) solar cells can achieve above $29 \%$ power conversion efficiencies based on the efficacy of wave-interference-based light trapping and carrier transport in parabolic-pore photonic-crystal. In addition, Sayak Bhattacharya et al. [93] demonstrate a geometry of a simple photonic crystal solar cell that enables the power conversion efficiency of a single junction c-Si solar cell to exceed the previous theoretical limits. The geometry of the designed thin-c-Si inverted pyramid-PhC solar cell is shown in Fig. 3.
Ping Kuang et al. [94] proposed and demonstrated a unique teepee like PC design with broadband, wide-angle near-unity solar energy absorption. The design is based on Gaussian-type gradient-index interface profile and near-orthogonal parallel-to-interface negative refraction. Fig. 4 shows the schematic representation of the teepee-like PC structure. The PC structure similar to teepee is realized by a unique but simple photolithography composition and RIE dry etching process. The process is repeatable and compatible with IC technology and can be used for large area, high throughput wafer-scale manufacturing.

The preparation process of three-dimensional photonic crystals. Three-dimensional photonic crystals with full band gaps are extremely difficult to prepare. Up to now, three-dimensional photonic crystal fabrication technology can be roughly divided into the following categories: dipping pen nanolithography, self-assembly of colloidal microspheres, multi-beam coherence, phase grating, grazing angle deposition technology, and combination of electron beam and reactive ion beam [21]. Jiang et al. [26] used surface tension of liquid to prepare face-centered cubic photonic crystals. The steps are as follows: insert the wave plate vertically into the colloidal solution to control the temperature and humidity of the solution. With the evaporation of the solvent in the colloidal suspension solution, the surface of the wave plate will naturally form face-centered cubic photonic crystals arranged periodically along the direction (111). The disadvantage of this method is that it may cause surface defects when subjected to external perturbations [21]. Subsequently, Blaaderan et al. [27] proposed a template method for preparing colloidal face-centered cubic photonic crystals with (100) crystal orientation. A photonic crystal composed of microspheres does not have a complete photonic band gap, and a complete photonic band gap can only be obtained when the refractive index of the inverse structure formed by inversion into an air ball is greater than 2.9 [21]. This inversion method is also called inverse opal method.

Commonly used inversion methods are chemical vapor deposition and atomic layer deposition. Three-dimensional photonic crystals with a complete photonic band gap in the near-infrared region have been produced by this method [24], but three-dimensional photonic crystals having a complete photonic band gap in the visible region have not yet been obtained. The introduction of different defects in a photonic crystal allows it to have different applications, such as introducing a line defect to make it an optical waveguide. Two-photon etching can be adopted to introduce defects in photonic crystals [21]. Three-dimensional photonic crystals with specific defects can be fabricated by combining electron beam direct writing, reactive ion beam etching, chemical vapor deposition, surface polishing and wet etching [26]. But this method is expensive and cumbersome, and once a step shows any defects, the whole process needs to be restarted [28].

In recent years, multi-beam coherent holography has also been

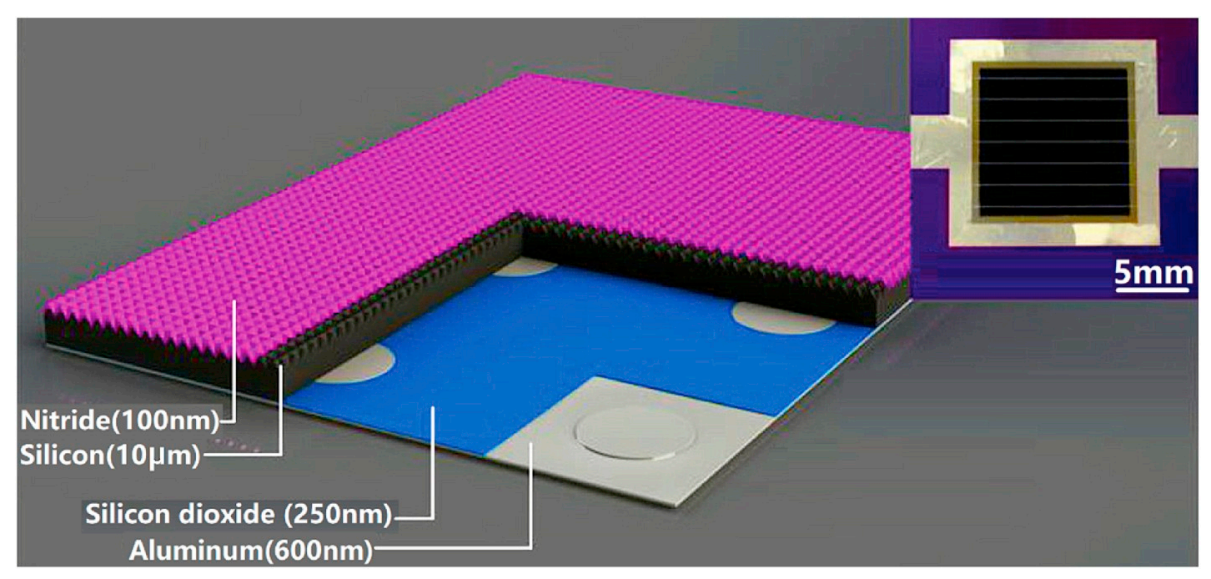

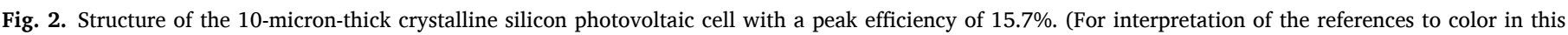
figure legend, the reader is referred to the Web version of this article.) 


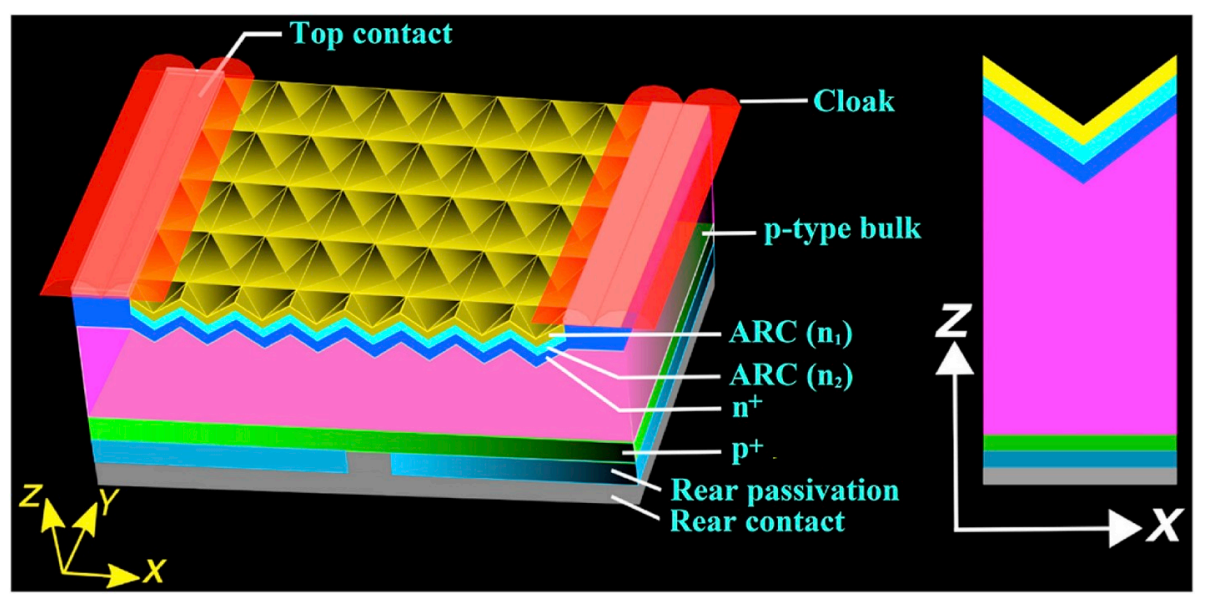

Fig. 3. The geometry of the designed thin-c-Si inverted pyramid-PhC solar cell.

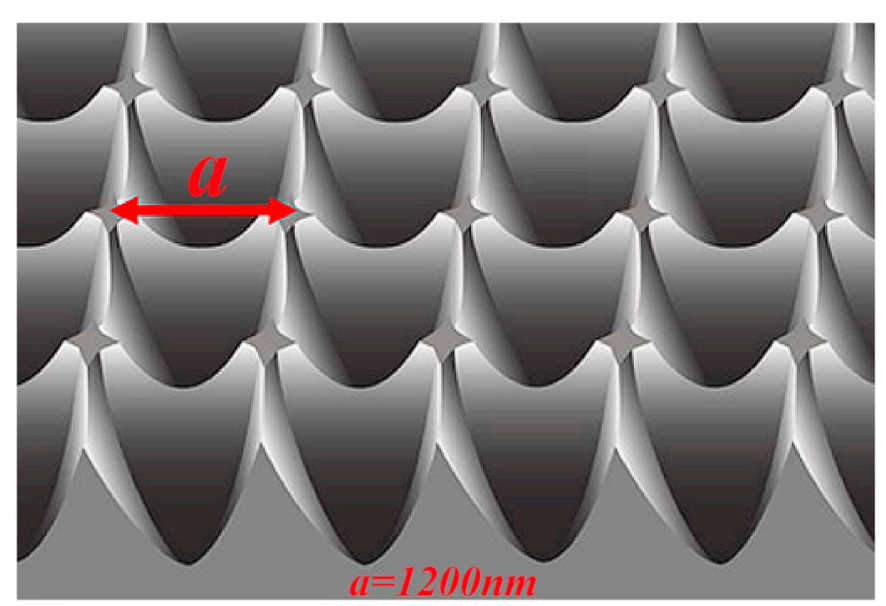

Fig. 4. Schematic representation of the teepee-like PC structure.

developed. Different lattices can be obtained by adjusting the phase and polarization of the beams, and almost all lattice types can be obtained, but the adjustment of multiple beams is very inconvenient [21]. The principle of dipping pen nanolithography is that high concentration of polymer electrolyte ink is controlled by computer and dripped into a storage tank through a capillary glass tube, the ink solidifies rapidly and then three-dimensional periodic microstructures with different structures and functions are etched directly onto the condensate. Large-size three-dimensional photonic crystals can be prepared using multi-beam coherence, but due to the limitations of the beam used, only photonic crystals with complete photonic band gaps in the near-infrared region have been produced so far. Hree dimensional photonic crystals in visible region are an important application field. By innovating and improving the preparation methods of three-dimensional photonic crystals, the fabrication of full photonic bandgap three-dimensional photonic crystals in the visible region will bring significant breakthroughs in this field [21].

Photonic Band-Gap (PBG) is the basic characteristic of photonic crystals. According to the Fermi's golden rule, the photons whose energy is consistent with the Photonic Band-Gap will be inhibited in their propagation and emission in the Photon Band-Gap. When the defect state is introduced into the photonic crystal, the photon state density at the defect state increases significantly, and spontaneous emission can be enhanced at the defect state position. In addition, in photonic crystals with defect states, photons are localized at the defect location, i.e. the optical localization characteristics of photonic crystals. Using this characteristics of photonic crystals, optical microcavities with high enhancement factor [6] and optical waveguides without loss can be fabricated [6]. At the edge of the band gap of the photonic crystal, the group velocity of photons approaches zero, which can form a standing wave and produce "slow photon" effect. Using this effect, the interaction between photons and matter can be enhanced [29]. It can be seen from Fig. 5 that the photons at the "red band edge" of the photonic crystal band gap are mainly concentrated at the high refractive index of the material, while the photons at the "blue band edge" are mainly concentrated at the low refractive index of the material [30]. Therefore, by regulating the distribution of functional materials in photonic crystals, photons can be efficiently utilized [6].

Photonic band gap and slow photon effect of photonic crystals can effectively enhance the efficiency of optical enrichment. Therefore, the photonic crystal structure can be introduced into the solar cell, and the optical properties of the photonic crystal can be used to improve the photoelectric conversion efficiency of the solar cell [6]. This method has received wide attention from scientists. The introduction of photonic crystals can improve the performance of solar cells in five aspects. First, photonic crystals are constructed as back mirrors, which can reduce the loss of light and increase the absorptivity [31]. Secondly, the "slow photon" effect of photonic crystals can improve the interaction between photons and sensitizers and enhance the excitation efficiency [6]. Third, photonic crystals can be used as scattering layers to increase the path of light propagating through matter. At the same time, resonance enhancement mode was formed in the absorption layer to improve the absorption efficiency [32], Fourth, photonic crystals have large specific surface areas, especially three-dimensional photonic crystals, which can provide excellent carriers for sensitizers. It can effectively increase the amount and activity of sensitized molecules and improve the photoelectric conversion efficiency of the cell. Fifth, Since the photonic band gap and slow photon effect of photonic crystal can effectively enhance the light enrichment efficiency of the material, the introduction of photonic crystal can reduce the dependence of the efficiency of solar cell (especially for dye sensitized solar cell (DSSC)) on the incident angle of sunlight [6].

\section{Application of photonic crystals in solar cells}

\subsection{Application of photonic crystals in silicon solar cells}

Shen Hongjun et al. [33] designed a thin film solar cell. The structural model is shown in Fig. 6. From top to bottom, anti-reflection layer, refractive index gradient medium layer, active layer and back reflection layer are sequentially arranged. The anti-reflection layer is a photonic crystal with a dielectric cylinder as a light cone structure, and $\mathrm{Si}_{3} \mathrm{~N}_{4}$ is filled on $\mathrm{SiO}_{2}$ as a substrate. The gradient refractive index dielectric layers are ITO and $\mathrm{TiO}_{2}$, respectively, which can effectively reduce the 

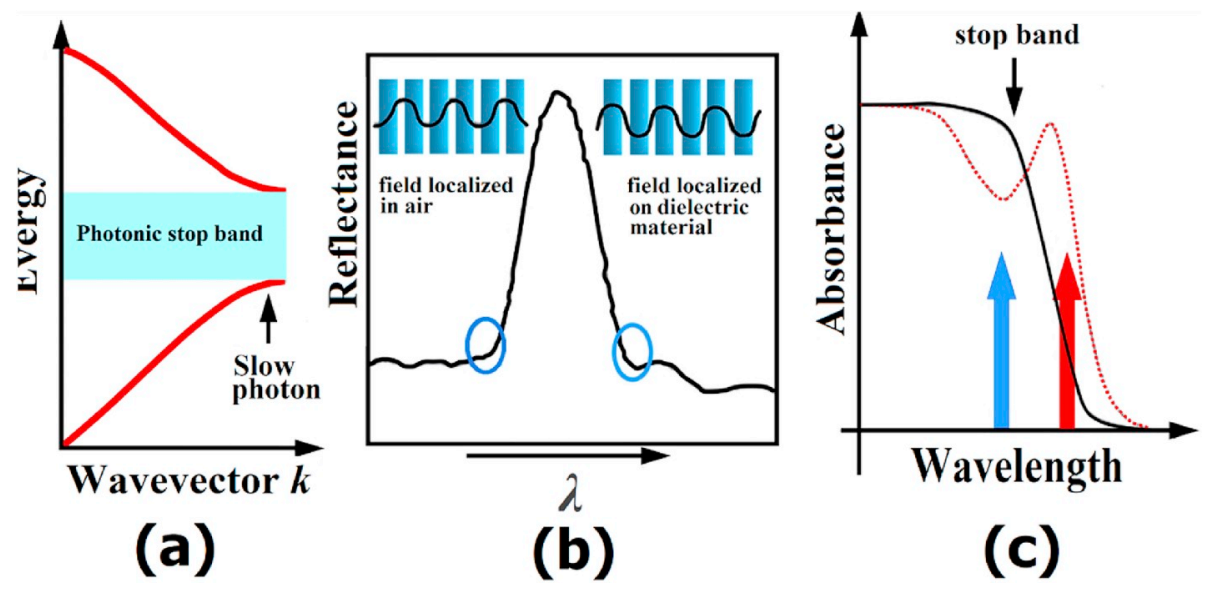

Fig. 5. (a b) A schematic diagram of a photonic crystal "slow pho-ton" Effect [29], (c) Illustration of the effect of standing wave localization on dye absorbance [30] http://kns.cnki.net/KXReader/Detail/GetImg?filename images/HXXB201801001_54100.jpg\&uid WEEvREcwSlJHSldRa1FhdkJkVWI3b 1ZxVHNkWDJaWUOrUDE2L1c3ZnlKTT0 \$9A4hF_YAuvQ5obgVAqNKPCYcEjKensW4ggI8Fm4gTkoUKaID8j8gFw!!

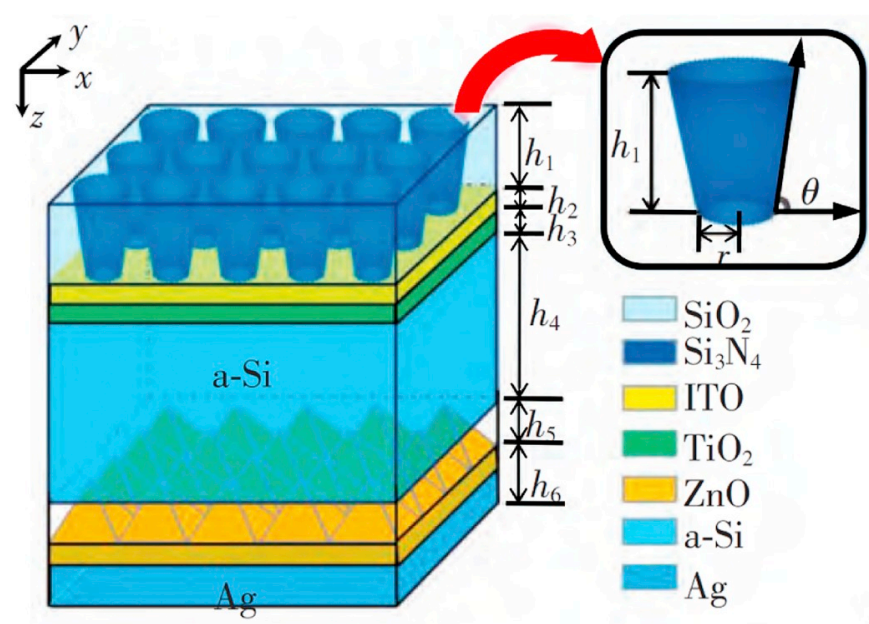

Fig. 6. Structural model of thin-film solar cells.

reflection of incident light; The active layer is the light absorbing layer, the material is a-Si; the back reflection layer is composed of a $\mathrm{ZnO}$ quadrangular pyramid subwavelength grating and an $\mathrm{Ag}$ substrate.

The refractive index of $\mathrm{Si}_{3} \mathrm{~N}_{4}$ is 2 . The refractive index of ITO is 1.9, The refractive index of $\mathrm{SiO}_{2}$ satisfies Cauchy model [33]: $\boldsymbol{n}_{\mathrm{SiO}_{2}} \lambda$ A $B / \lambda^{2} \quad C / \lambda^{4}$, where A $1.491, \mathrm{~B} \quad 0.00686, \mathrm{C} \quad 0.0007648$. The refractive index of $\mathrm{SiO}_{2}$ the formula [33]: $\boldsymbol{n}_{\mathrm{TiO}_{2}} \lambda$ $\sqrt{5.913} \frac{0.2441 \lambda^{2}}{\lambda^{2} 0.0803}$

The refractive index of $\mathrm{ZnO}$ satisfies formula [222]:

$\boldsymbol{n}_{\text {ZnO }} \lambda \quad \sqrt{2.81418} \frac{0.87968 \lambda^{2}}{\lambda^{2} 0.3042^{2}} \quad 0.00711 \lambda^{2}$

The following results were obtained using the RCWA method: when the structure angle of the light cone $\theta 72$, lattice constant $\mathrm{T}_{1} \quad 1200 \mathrm{~nm}$ and medium base radius $\mathrm{r} 100 \mathrm{~nm}$, the anti-reflection layer transmission efficiency is relatively high, and the structure improves the average absorption efficiency of the thin-film solar cell in the wavelength range of $300-600 \mathrm{~nm}$ by $11.54 \%$. When the period of the quadrangular pyramid grating $\mathrm{L} \quad 1.2 \mu \mathrm{m}$, the duty ratio $\mathrm{f} \quad 0.38$, and the groove depth $\mathrm{h}_{5} \quad 560 \mathrm{~nm}$, the reflection effect of the back reflection layer is better. The average absorption efficiency of the cell increased by $3.75 \%$ in the wavelength range of $600-850 \mathrm{~nm}$. Moreover, the absorption efficiency of the thin-film cell structure is above $80 \%$ when the wavelength is $300-750 \mathrm{~nm}$ and the incidence Angle is $0 \sim 75$, and the average absorption efficiency is $92 \%$. Compared with thin film solar cells without trapping structure, the designed solar cell structure enhances light absorption in the visible wavelength range and wide angle [33].

Crystal silicon (c-Si) has weak absorption in the near infrared region [6]. $36.2 \%$ of solar energy cannot be absorbed because it is higher than the indirect band gap of crystalline silicon [22]. In contrast to this sentence, if the photon energy is higher than the bandgap, it should be absorbed. In order to improve the photo enrichment efficiency of crystalline silicon solar cells, photo-enrichment structures are usually introduced into crystalline silicon solar cells. There are two main types of optical structures commonly used at present: geometric optics and grating/photonic crystal optical structures based on wave optics [6]. The traditional geometrical optical enrichment method improves the efficiency of photon capture by increasing the path of incident light in the cell. By etching, scattering patterns can be formed on the surface of silicon cells and a reflective coating can be deposited. This can effectively reduce the reflection of light and increase the scattering of light. In addition, a metal mirror on the back of the silicon cell can reflect projected light back into the cell. Through the synergistic effect of reducing reflection, scattering and suppressing transmission, the path of incident light can be greatly increased, so that the efficiency of light enrichment is improved [6].

However, there are many limitations in the optical enrichment methods of geometric optical structures. For example, the actual surface scattering ripple-Lambertian fraction is usually less than $55 \%$ [6], the filling factor of silicon cell with scattering pattern is $6.7 \%$ lower than that of traditional silicon cell [6], and the reflectivity of the metal mirror on the back is about 90\% [34]. Therefore, in order to further improve the absorption of solar energy by silicon cells, a light enrichment structure based on wave optics has been introduced.

There are three main types of optical enrichment methods based on wave optics. The first is coupling light to the inside of the cell by resonant modes formed by surface plasmas in a specific wavelength range. The second is the formation of gratings inside the cell to increase the effective path of light through the diffraction of the gratings. The first gratings used are metal gratings, which can enhance the absorption of light energy by the cell, but do not contribute much to the efficiency of the photovoltaic conversion of the cell [6]. Then the dielectric grating with planar metal mirror is used to improve the overall efficiency of the cell significantly $[6,35]$. In order to reduce the energy loss caused by metal back reflector, one-dimensional photonic crystal (DBR) is used in combination with grating [36-38]. The third is to use the "slow photon" effect of photonic crystals to enhance the absorption of photosensitized 
solar cells $[6,38]$.

Several different photonic crystal photo enrichment structures based on the principle of wave optics have been designed by Bermel P. et al. [31]. It is found that the absorption efficiency of crystal silicon in the near infrared wavelength range of $700-1100 \mathrm{~nm}$ can be greatly improved by the introduction of photonic crystals. They have prepared $\mathrm{SiO}_{2} / \mathrm{c}$-Si one-dimensional photonic crystals by plasma enhanced chemical vapor deposition (PECVD). They have designed four types of light-enriched structures using three types of photonic crystal structures. The first is to combine six periods of one-dimensional photonic crystal (DBR) with one-dimensional grating to form a "DBR-1D grating" structure. The second is to combine six periods of one-dimensional photonic crystal (DBR) with two-dimensional grating to form a "DBR-2D grating" structure. The third is to replace the "DBR-grating" structure with six periodic two-dimensional photonic crystals. The fourth is the formation of 3D opal photonic crystals with face-centered cubic (FCC) lattice structure in c-Si. The overall efficiency of the crystal silicon solar cells corresponding to these four types of structures are $15.41 \%, 16.32 \%$, $15.70 \%$, and $15.73 \%$, respectively [6].

The reflection and diffraction of the "DBR-grating" photoenrichment structures and photonic crystal photo-enrichment structures have contributed greatly to the improvement of the efficiency of the cell [6]. In addition, the depth of scattering fringes is generally $5 \mu \mathrm{m}$, and photonic crystals can be made up of several layers of materials about $300 \mathrm{~nm}$ thick, therefore, the introduction of photonic crystals is more conducive to reducing the thickness of the cells. Compared with ordinary silicon solar cells, photonic crystal silicon solar cells have more obvious light enrichment effect when using the same material. Therefore, the introduction of visible light crystals is more conducive to improving the efficiency of crystalline silicon solar cells [6].

\subsection{One-dimensional photonic crystal sensitized solar cells}

A one-dimensional photonic crystal is formed by periodically stacking two dielectric layers having different dielectric constants. Its characteristic is that it can produce one-dimensional photonic band gap [39]. Light with energy in the forbidden band cannot propagate, so that light is well reflected on the surface of a one-dimensional photonic crystal [40], therefore, it is very suitable for use as a back reflector for solar cells. Conventional silverback reflectors have high reflection efficiency, but because of their high cost, solar cell reflectors often use aluminum as a substitute for silver in mass production. However, due to the poor light trapping effect of aluminum, the overall efficiency of the solar cell is not high, and it is necessary to select a more suitable substitute for the reflector material of the solar cell [39].

The introduction of one-dimensional photonic crystals can enhance the charge transport performance, reduce the recombination rate of electron-hole pairs, and improve the transparency of the devices [41-43]. Since the arrangement of one-dimensional photonic crystals can be easily optimized, this one-dimensional design can be theoretically rigorously calculated to draw conclusions.

Miguez et al. [6] alternately spin-coated $\mathrm{TiO}_{2}$ and $\mathrm{SiO}_{2}$ nanoparticles to form one-dimensional $\mathrm{TiO}_{2} / \mathrm{SiO}_{2}$ photonic crystals. The thickness of the coating can be changed by adjusting the concentration and rotational speed of the precursor solution, thus the one-dimensional $\mathrm{TiO}_{2} / \mathrm{SiO}_{2}$ photonic crystals with different band gaps is constructed. First, the one-dimensional photonic crystal of $\mathrm{TiO}_{2} / \mathrm{SiO}_{2}$ with a thickness of $500 \mathrm{~nm}$ is combined with the layer of $\mathrm{NC}^{-\mathrm{TiO}_{2}}$ with a thickness of $7.5 \mu \mathrm{m}$. Then the photoelectric conversion efficiency of the dye-sensitized cell can reach $4.6 \%$ by using the "slow photon" effect of photonic crystal and the resonator formed by a photonic crystal and $\mathrm{NC}-\mathrm{TiO}_{2}$ layer [41]. Next, the flexible one-dimensional $\mathrm{TiO}_{2} / \mathrm{SiO}_{2}$ photonic crystal thin film is permeated into the gap. The thin film can be stripped from the substrate without damaging its optical properties [6]. However, the insulation of $\mathrm{SiO}_{2}$ nanospheres is not conducive to charge transmission. In the same year, the team abandoned the $\mathrm{SiO}_{2}$ coating.
They controlled the porosity of adjacent layers of $\mathrm{TiO}_{2}$ by adjusting the spin-coating rate, the concentration of the precursor solution and the size of $\mathrm{TiO}_{2}$ nanoparticles. Then, they obtained $\mathrm{TiO}_{2}$ coating with two effective refractive index and forming one-dimensional photonic crystals of $\mathrm{TiO}_{2}$. Next, the photoelectric conversion efficiency of the cell was increased by $45 \%$ by increasing the porosity [6] or the period of the one-dimensional photonic crystal [43]. However, because the pores in one-dimensional photonic crystal and nanocrystalline layer are too dense, the dye and liquid electrolyte cannot be permeated completely, which greatly restricts the photoelectric conversion efficiency of the cell.

Lu Xiaodong et al. [44] designed an ultrathin silicon solar structure based on one-dimensional photonic crystals (Fig. 7). They optimized the theoretical calculation of the trapped structure of ultra-thin crystalline silicon cells with a thickness of $12 \mathrm{~mm}$ using the finite-difference frequency domain method. The results show that the average optical absorption efficiency of this kind of thick cell can be increased by more than 2 times compared with the bare silicon wafer by using anti-reflection film, silver back reflector and photonic crystal surface texture structure, and the maximum optical current density can reach more than $33 \mathrm{~mA} / \mathrm{cm}^{2}$, but the angular tolerance of this design needs to be further improved [39].

In order to more realistically describe the performance of photonic crystals in solar cells, such structures should be fabricated after the optimization calculation is completed, and verified in actual tests [39]. Chen Peizhuo et al. [45] designed and fabricated a one-dimensional photonic crystal model with alternating arrangement of $\alpha-\mathrm{Si}$ and $\mathrm{SiO}_{\mathrm{x}}$ (Fig. 8). They used the finite-difference time-domain method to select the appropriate band gap range of one-dimensional photonic crystals alternately arranged by $\alpha-\mathrm{Si}$ and $\mathrm{SiO}_{\mathrm{x}}$, and pointed out that the band gap width reached the maximum when the thickness ratio of $\alpha-\mathrm{Si}$ and $\mathrm{SiO}_{\mathrm{x}}$ was between $1 / 2$ and $2 / 3$. Based on the simulation results, they fabricated a series of one-dimensional photonic crystal solar cell reflectors that consist of $\alpha$-Si layers with thickness from 25 to $60 \mathrm{~nm}$ by chemical vapor deposition (CVD). The experimental results show that in the wavelength range of $500-750 \mathrm{~nm}$ and $650-1100 \mathrm{~nm}$, the optical reflectance reaches $96.4 \%$ and $99 \%$ respectively, and the efficiency of the fabricated solar cell reaches $15.2 \%$.

Shen Hongjun et al. [46] designed an $\alpha$-Si structure containing a photonic crystal anti-reflection layer and a quad-pyramid back-reflection layer. The results show that the absorption efficiency of the membrane cell structure is above $80 \%$ and the average absorption efficiency is $92 \%$ when the wavelength is $300-750 \mathrm{~nm}$ and the incidence angle is $0-75$. Compared with thin-film solar cells without trapping structure, the designed solar cell structure enhances light absorption in the visible wavelength range and wide angle. The above two structural advantages are simple in structure, easy to optimize calculations, and easy to manufacture. However, due to the photonic crystal is produced by chemical vapor deposition, the film thickness and composition uniformity are good, the film structure is dense, and pinholes are small, which leads to a reduction in effective optical path [39].

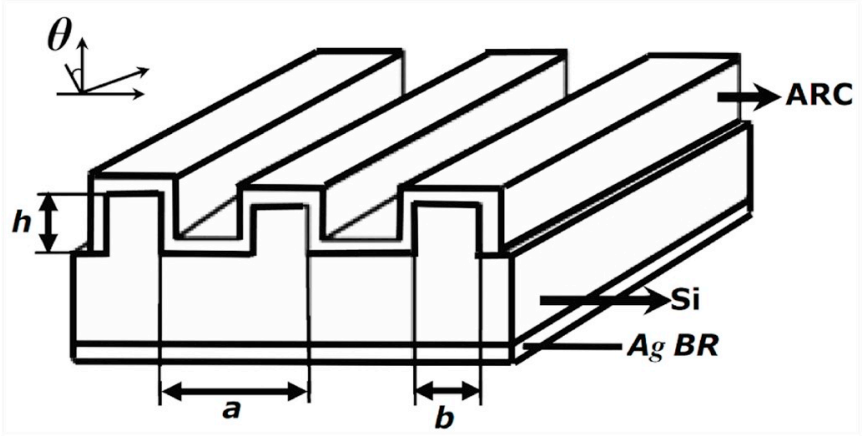

Fig. 7. Schematic diagram of ultra-thin crystalline silicon cell structure. 


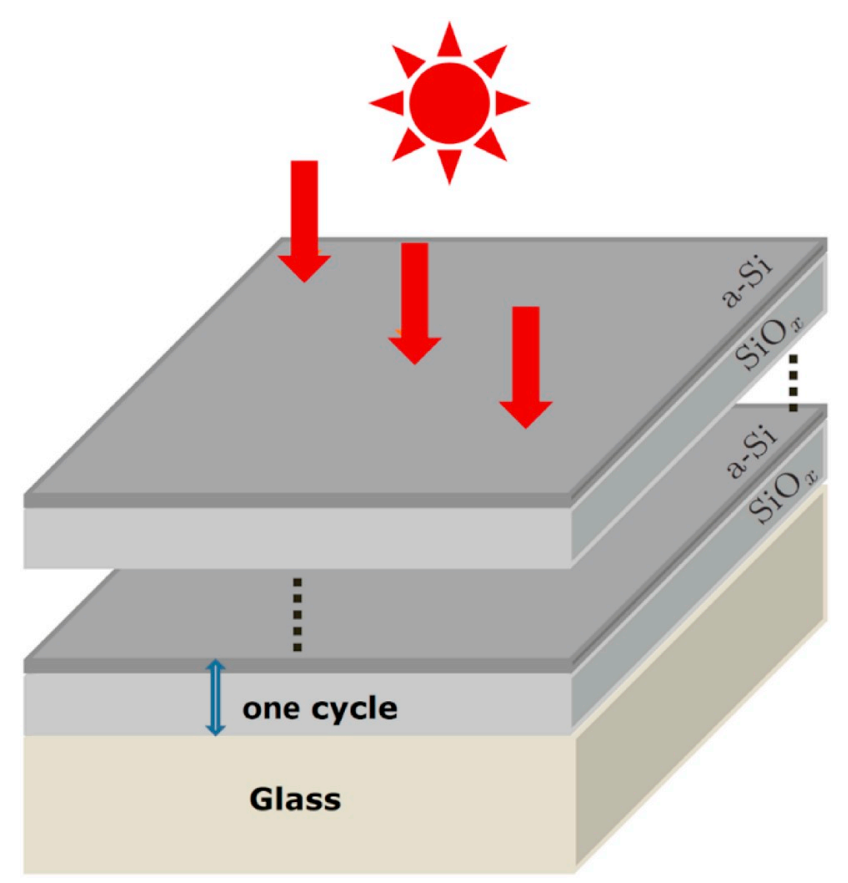

Fig. 8. One-dimensional photonic crystal model with alternating arrangement of $\alpha-\mathrm{Si}$ and $\mathrm{SiO}_{\mathrm{x}}$.

Song et al. [47] used ITO (Indium Tin Oxide) and ATO (Antimony-doped tin oxide) to form one-dimensional photonic crystals. They replaced the ITO layer between the photonic crystal and the silver electrode with an organic layer of P3HT: PCBM (Poly-3-hexylthiophene phenyl-C61-butyl) about $40 \mathrm{~nm}$ thick to form PC-OSC (organic solar cells). As shown in Fig. 9a. In this way, the optical Tamm state (OTS) can be produced between the organic layer and the silver electrode. Different from surface plasmas, OTS can be directly excited by TE or TM polarized light in air [6]. Compared with the conventional planar organic solar cell (Fig. 9b), the introduction of OTS can increase the light absorption of the cell by 35\% (Fig. 9e) in the full spectrum range. In addition, it can enhance the incident light of TE and TM polarized states, and the maximum intensity of TM polarized light is achieved at the metal/organic interface (Fig. 9d).

Many researchers have combined the photonic crystal structure with the grating structure to make up for the lack of structural properties of a single photonic crystal. The design of this structure is usually applied to solar cells with multiple junctions. The James G. Mutit's team designed a multi-junction solar cell $[39,48]$. Fig. 10 shows a partial structure of the multi-junction solar cell, the uppermost is an anti-reflection layer. It is made up of $\mathrm{Si}_{3} \mathrm{~N}_{4}$ embedded in upper and lower layer of $\mathrm{SiO}_{2}$, the purpose is for passivation. Below the anti-reflection layer is a $\mathrm{SiO}_{2}$-and-Si grating structure. The short-wave reflection layer is a connection structure of a one-dimensional photonic crystal composed of $\mathrm{Si}$ and $\mathrm{SiO}_{2}$ and a triangular grating. The lowest layer is a one-dimensional photonic crystal long wave absorption reflection layer composed of $\mathrm{Si}$ and $\mathrm{SiO}_{2}$. The grating structure is made by electron beam lithography. The bottom photonic crystal structure is prepared by plasma enhanced chemical vapor deposition. The absorption rate of the solar cell reaches $77 \%$ at $400-1100 \mathrm{~nm}$, the short-circuit current reaches $30.25 \mathrm{~mA} / \mathrm{cm}^{2}$, the enhancement factor at the edge of the band $(867-1100 \mathrm{~nm})$ reaches 4.6 , and the transmission efficiency reaches $41 \%$ at $1100-1800 \mathrm{~nm}$.
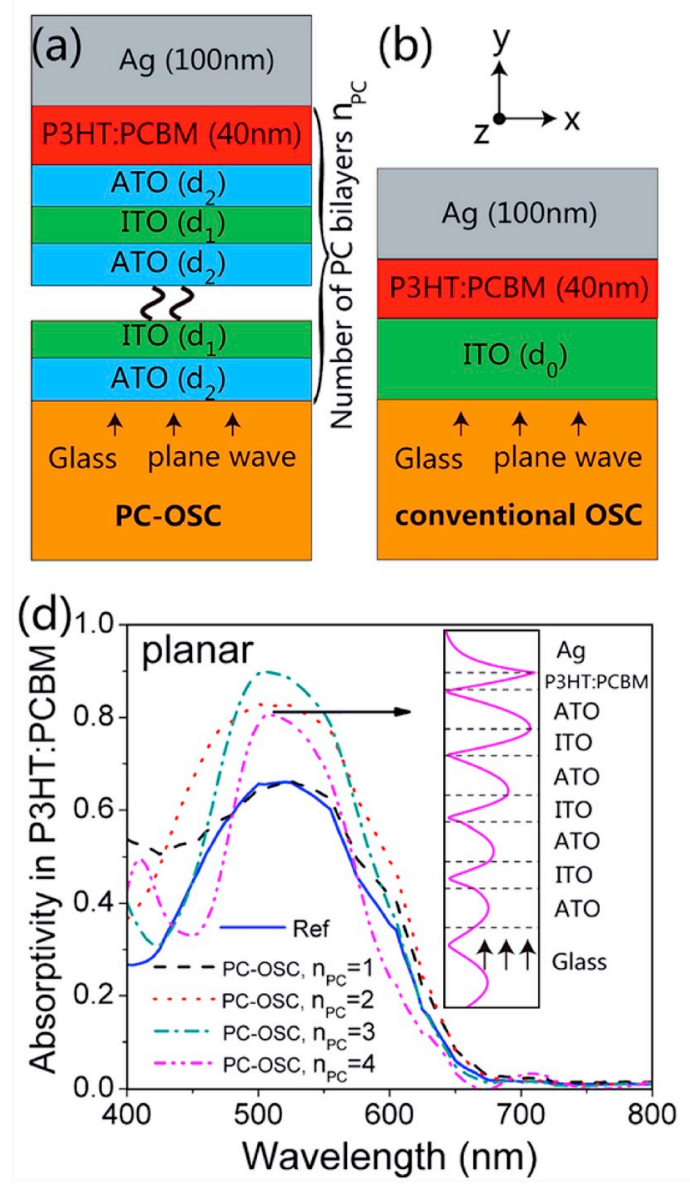
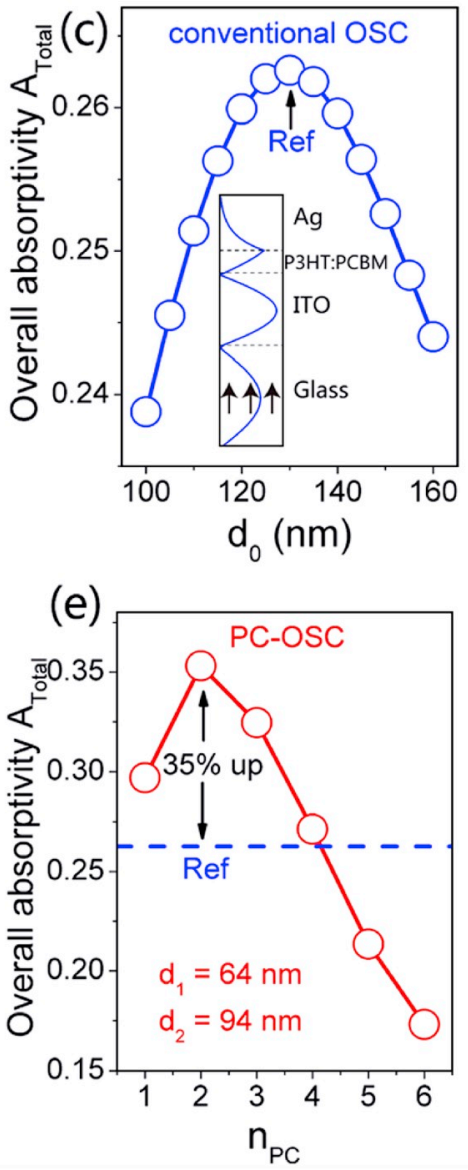

Fig. 9. Optical Tamm mode enhances the light absorption of organic solar cells [41]. 


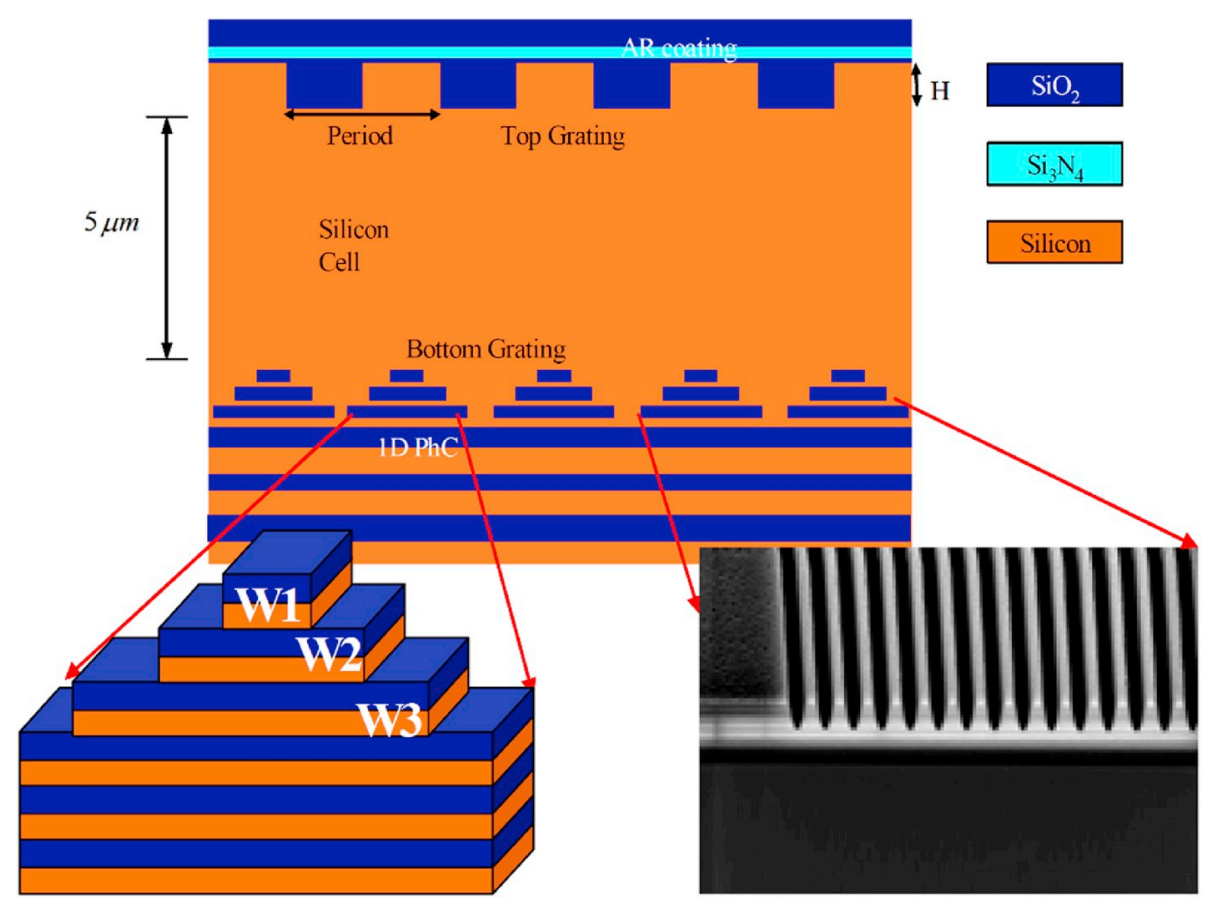

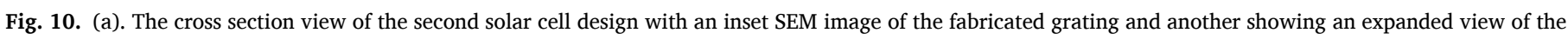
grating, the grating widths are indicated and the values are W1 $104 \mathrm{~nm}$, W2 $312 \mathrm{~nm}$, W3 $416 \mathrm{~nm}$.

In recent years, the emergence of perovskite solar cell (PSC) has made rapid development in the field of solar cells [6]. Perovskite has the advantages of a high absorption coefficient, wide absorption spectrum, tunable band, and long exciton diffusion distance. It is beneficial to improve the photoelectric conversion efficiency of the device and reduce the preparation cost [49-55]. The structure of PSC is mainly divided into a perovskite-sensitized mesoporous structure, planar heterostructure and inverted structure [56]. Despite the high conversion efficiency of PSC, PSC has a limited variety of colors and lacks green and blue [6]. Therefore, in order to broaden the color gamut of PSC, it is usually used to adjust the composition of the perovskite crystal or the structural color of the photonic crystal. Physical colour, also known as structural color, is a gloss caused by the wavelength of light.

Snaith et al. [57] introduced $\mathrm{TiO}_{2} / \mathrm{SiO}_{2}$ one-dimensional photonic crystals as active layers into PSC. Under the condition of keeping high reflectivity, the microstructure of $\mathrm{TiO}_{2}$ and $\mathrm{SiO}_{2}$ layers are optimized to reduce the thickness of the PC layer. On the other hand, they used photonic crystal structure color to realize multicolor non-transparent PSCs with blue, blue-green and green hues. At the same time, the photonic crystal can reflect the incident light at a specific frequency and reduce the thermal gain in PSC, which is beneficial to enhance the conversion efficiency of practical applications [6]. Therefore, the introduction of PC allows PSC to have more functions to expand its application range.

Zheng's group [58] designed a multi-junction solar cell structure. The structure is a combination of a grating and a one-dimensional photonic crystal composed of crystalline silicon and silicon dioxide. It uses gratings to increase its effective optical path. The design of this structure has been perfected. Modifications based on this are limited only to the choice of materials and the optimization of the thickness of some structures [39].

Ahmad et al. [59] used angular physical deposition (PVD-OAD) to accurately control the growth of nanorods. They prepared three kinds of one-dimensional photonic crystals that could be used as PSC photoanode by controlling the tilt angle of PVD-OAD, the thickness of monolayer films and using different metal oxides. They obtained PSC with PCE of $10.94 \%, 6.39 \%$, and $12.03 \%$ respectively.
Polymer solar cells, as an important category of the next generation of new thin-film solar cells currently studied, have attracted wide attention in recent years, and their energy conversion efficiency has reached more than 13\% [61]. Luo Guoping et al. [60] systematically designed a one-dimensional photonic crystal with different Bragg reflection wavelength and applied it to translucent polymer solar cells. The bulk heterojunction active layer of the translucent polymer solar cell is PTB7-Th:PC71BM $(90 \mathrm{~nm})$. Fig. 11 (a) shows the chemical structural formula of PTBT-Th and PC71BM. PTB7-Th is a narrow bandgap donor material first reported in 2013. Its chemical structure is shown in Fig. 11 (a). Its band gap is $1.58 \mathrm{eV}$, and its main absorption region is $500-785 \mathrm{~nm}$ [62]. The translucent polymer solar cell has an inverted structure as shown in Fig. 11 (b). Glass/ITO is used as the bottom electrode, ultra-thin $\mathrm{Ag}(10 \mathrm{~nm})$ is the transparent top electrode, PFN $(10 \mathrm{~nm})$ is the electron transport layer, and $\mathrm{MoO}_{3}(10 \mathrm{~nm})$ is the hole transport layer. The $\mathrm{MgF}_{2}(10 \mathrm{~nm})$ coated on $\mathrm{Ag}$ is the optical matching layer. $\mathrm{MoO}_{3}$ and $\mathrm{MgF}_{2}$ are used as high refractive index layer and low refractive index layer respectively in 1D PCS. The optical simulation results show that the optical band gap effect of the one-dimensional photonic crystal can improve the light absorption efficiency of the translucent device and maintain a certain transparency; semi-transparent devices using one-dimensional photonic crystals have higher short-circuit current density and average visible light transmittance over 20\%; by changing the Bragg wavelength of one-dimensional photonic crystals, translucent devices with blue, red and blue-green transmission colors can be fabricated, this provides an idea for the application of translucent polymer solar cells in photovoltaic building integration [60].

\subsection{Two-dimensional photonic crystal sensitized solar cells}

The fabrication of two-dimensional photonic crystals is more complicated than that of one-dimensional photonic crystals [39]. The lattice size of photonic crystals is similar to the wavelength of light, so the longer the wavelength of light at the center of the forbidden band is, the easier the photonic crystal are to be manufactured. At present, the fabrication techniques for two-dimensional photonic crystals are as 


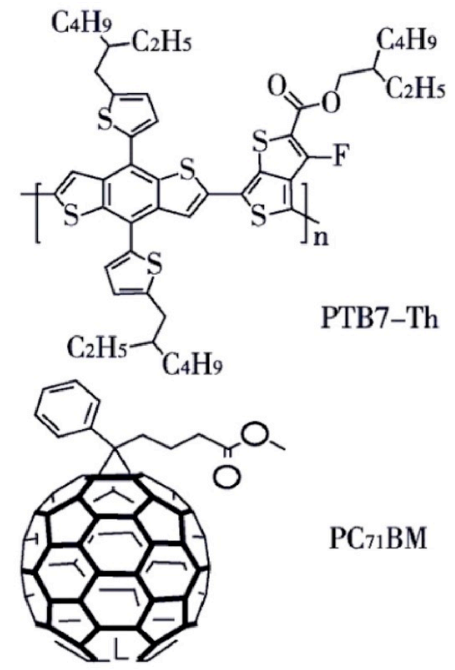

(a) material structure

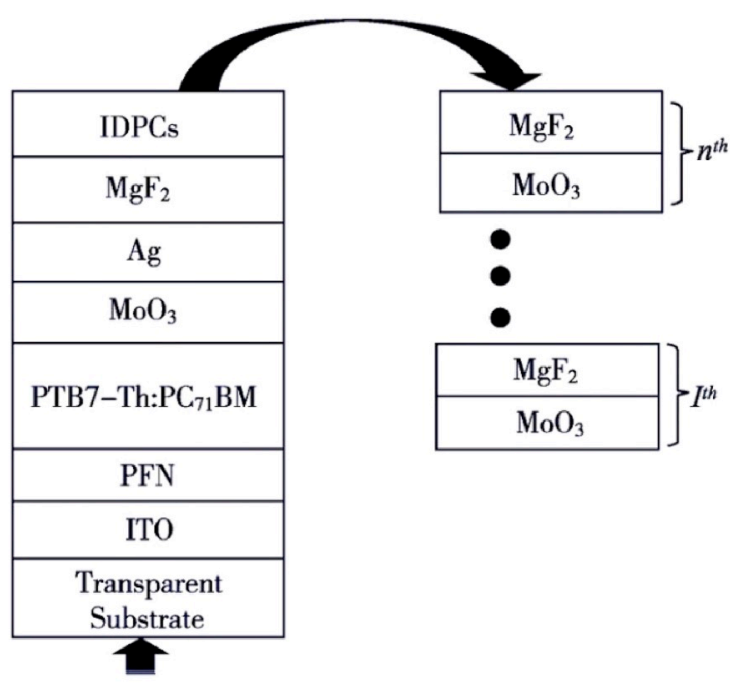

(b) cell structure

Fig. 11. Material structure and cell structure.

follows: Dielectric strip deposition, electron beam ion beam etching, and the method of electrochemical etching anodized aluminum oxide, etc. For the microwave band, it can be fabricated by mechanical processing [63]. For a specific pattern of photonic crystal, it can be fabricated by etching method $[64,65]$.

Two-dimensional photonic crystals are composed of materials with different dielectric constants arranged alternately in two-dimensional spaces. The 2D PCS consists of nanotube array (NTA), twodimensional porous structure [66,67], monolayer opal structure [68], honeycomb scaffold and a series of microstructures. Compared with $\mathrm{TiO}_{2}$ nanoparticles, $\mathrm{TiO}_{2} \mathrm{NTA}$ can transfer along the long axis of the nanotube wall, and reduce exciton recombination at the intergranular interface $[6,69]$. Moreover, it has a high specific surface area [6]. Therefore, $\mathrm{TiO}_{2}$ NTA can effectively improve the photoelectric performance of the cell.

At present, there are two main types of two-dimensional photonic crystals used in solar cells: one is an air hole structure having a dielectric constant of 1 , and the other is a dielectric column structure having a large dielectric constant. For example, dielectric cylinder type, dielectric pore triangle type and dielectric pore hexagonal type, etc. [70], as shown in Fig. 12a and Fig. 12b. This structure is widely used, and the structure is easy to form a complete forbidden band. Generally, the most used material in solar cells is silicon. For scattering elements, cylindrical and circular holes are the most widely studied, and the optimization calculation method is also relatively perfect [39].

$\mathrm{TiO}_{2} \mathrm{NTA}$ is usually prepared by anodic treatment. Doped with different elements, $\mathrm{TiO}_{2}$ NTAs has different optoelectronic properties. Keller et al. [71] prepared $\mathrm{TiO}_{2} \mathrm{NTA}$ by anodic treatment. They added ammonium fluoride niobate $\left(\left(\mathrm{NH}_{4}\right)_{5}\left[\left(\mathrm{NBOF}_{4}\right)\left(\mathrm{NbF}_{7}\right)_{2}\right]\right)$ to the electrolyte and the obtained NTA was heat-treated in $\mathrm{NH}_{3}$ atmosphere. Thus, $(\mathrm{Nb} / \mathrm{N})$ co-doped $\mathrm{TiO}_{2} \mathrm{NTA}$ can be obtained. In this method, anion and cationic co-doping can be realized without special alloy plate. The concentration of $\mathrm{Nb}$ element can be changed in a wide range by controlling the concentration of ammonium fluoride niobate and water in the electrolyte. Compared with $\mathrm{N}$-doped $\mathrm{TiO}_{2} \mathrm{NTA}$ and $\mathrm{Nb}$-doped $\mathrm{TiO}_{2} \mathrm{NTA}$, (Nb/N) co-doped $\mathrm{TiO}_{2} \mathrm{NTA}$ can greatly improve the photoconversion efficiency of the cell in the UV-Vis range. Guo et al. [72] prepared aperiodic $\mathrm{TiO}_{2}$ NTA photonic crystal by applying a current pulse with periodic variation as an equal difference sequence, which is known as Aperiodic Photonic Crystal. The change of reflectance spectrum corresponding to APC is an arithmetic progression. The method is characterized by high controllability and strong reproducibility. The photoanode with aperiodic $\mathrm{TiO}_{2} \mathrm{NTA}$ APC as DSSC can increase the
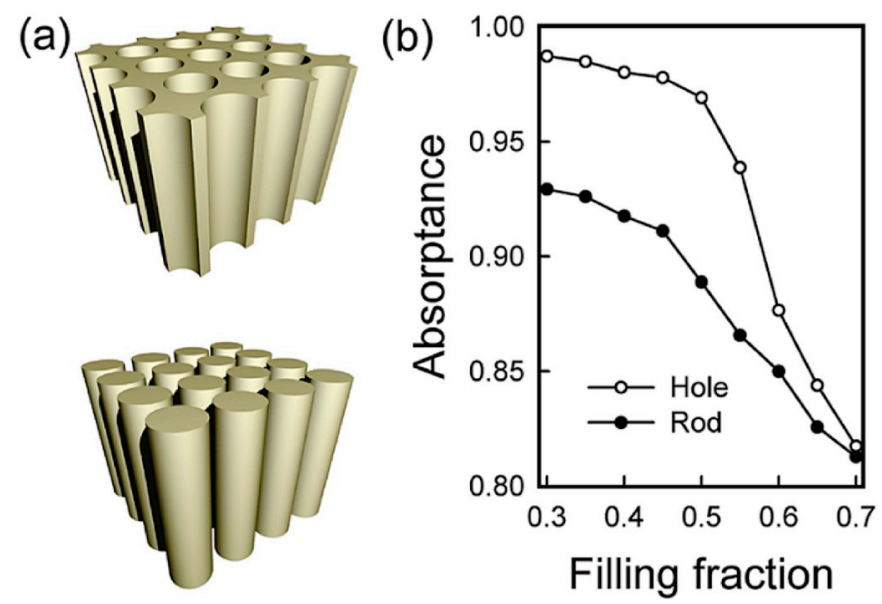

Fig. 12. (a) Schematic illustrations of nanohole and nanorod arrays. Light is incident from above. (b) Calculated absorptance at $\lambda \quad 670 \mathrm{~nm}$ as a function of c-Si filling fraction for the nanohole and the nanorod array structures occupying a half space.

photocurrent density by $0.27 .01 \%$ compared with reference DSSC. The $\mathrm{TiO}_{2} \mathrm{NTA}$ photonic crystal $\left(\mathrm{TiO}_{2} \mathrm{NTA} \mathrm{PC}\right)$ can also be obtained by applying periodic current pulse. Zhou et al. [69] prepared Seamless bonding between $\mathrm{TiO}_{2} \mathrm{NTA}$ and $\mathrm{TiO}_{2} \mathrm{NTA}\left(\mathrm{TiO}_{2} \mathrm{NTA}\right.$ PC-NTA) by applying a constant current pulse and periodic current pulse (Fig. 13 [69]). $\mathrm{TiO}_{2} \mathrm{NTA}$ is used as a part of the absorption layer and $\mathrm{TiO}_{2} \mathrm{NTA}$ PC is used as a PC layer. The advantages of this method are that the physical contact between the absorption layer and the PC layer can be enhanced, the filling factor can be increased, the pore clogging between the double electrodes can be avoided and the photonic band gap can be adjusted continuously to obtain the best light enrichment effect.

Compared with the DSSC with the same dye, this method eventually improves the photoelectric conversion efficiency by 50\% (Fig. 14). Huang et al. [73] obtained $2.3 \mu \mathrm{m}$ thick $\mathrm{TiO}_{2}$ NTA PCs by using periodic current pulses and then deposited them on the $\mathrm{NC}^{-\mathrm{TiO}_{2}}$ layer to form a double-layer photoanode (Fig. 15). This method can accurately adjust the photonic band gap to achieve the maximum PCE. Compared with the Gratzel cell, the photoconversion efficiency is $6.96 \%$ when the photonic band gap matches the absorption peak of the dye molecule.

Zhou jianwei et al. [74] calculated in detail the excellent optical 


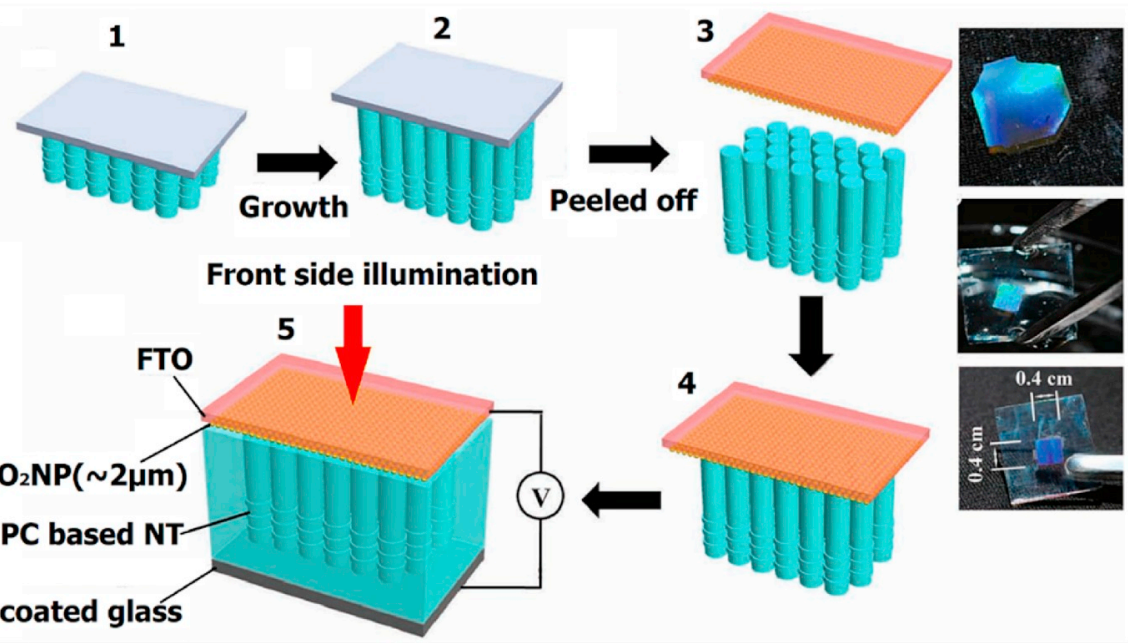

图 8 (a)[69]

Fig. 13. Schematic of the cell fabrication process [69].

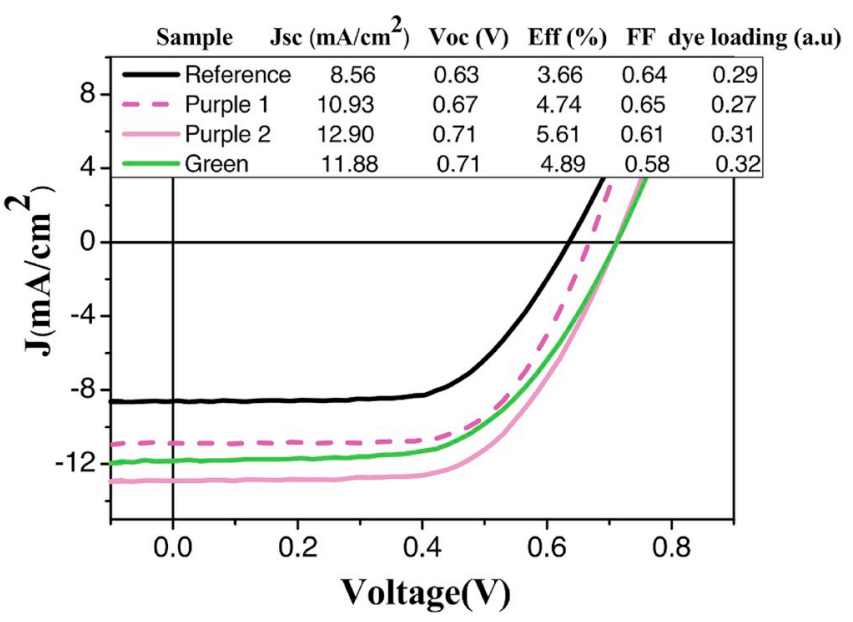

Fig. 14. Photocurrent-voltage curves under AM 1.5 solar light illumination. Four cells, namely purple 1 , purple 2 , green, and reference were tested. The axial lattice parameters in the PC layer of the purple and green cells are $\sim 150$ and $\sim 190 \mathrm{~nm}$, respectively. The numbers of periods for the PC layer of the purple and green cells are 30 and 20, respectively, and the corresponding HC pulse durations (tHC) are 28 and $40 \mathrm{~s}$, respectively. Purple 1 and purple 2 are similar cells with a slight difference in dye loading. The reference cell is similar to the others except for the exclusion of the PC layer [69]. (For interpretation of the references to color in this figure legend, the reader is referred to the Web version of this article.) absorption properties of nanowire arrays. They point out that the reflectivity of light decreases considerably after multiple reflections (Fig. 16) between nanowires. The experimental results show that the actual reflectivity of nanowires is lower than the theoretical value because the top of nanowires is not a completely flat and smooth platform. By measuring the prepared samples, it was found that a low reflectance of $2.4 \%$ was obtained in the $300-1100 \mathrm{~nm}$ band, which confirmed the excellent optical anti-reflection performance of the nanowire array theoretically and experimentally [39].

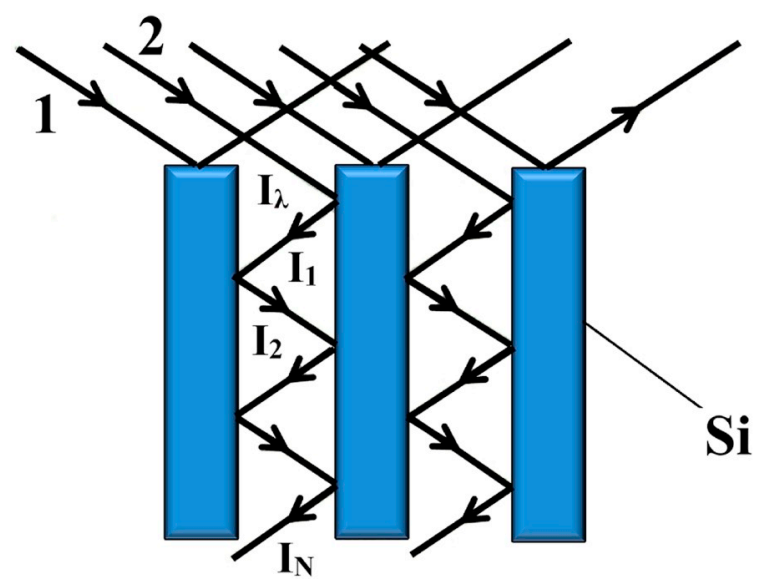

Fig. 16. Schematic diagram of light reflected in nanowire arrays.

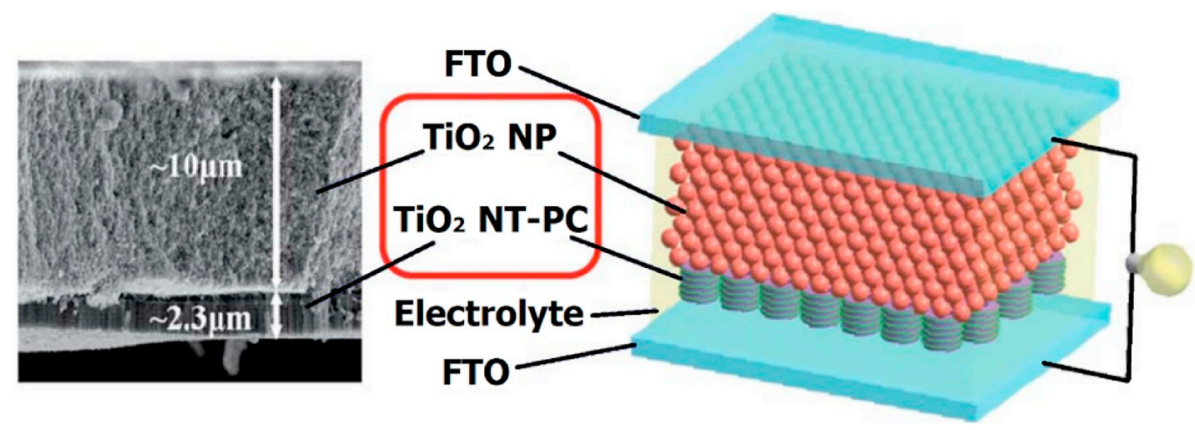

Fig. 15. Design of a DSSC based on the $\mathrm{TiO}_{2} \mathrm{NT} \mathrm{PC} / \mathrm{TiO}_{2} \mathrm{NP}$ photoanode and the SEM image of the $\mathrm{TiO}_{2} \mathrm{NT} \mathrm{PC} / \mathrm{TiO}_{2} \mathrm{NP}$ photoanode [73]. 
Moreover, Kelzenberq's group [75] has demonstrated experimentally that regular periodic nanowire arrays have better optical absorption than quasi-periodic or randomly distributed nanowire arrays, which is due to the strong anisotropic angular absorption of silicon nanowire arrays. However, the large specific surface area of this structure leads to the loss of carrier recombination of nanowires, which is also an urgent problem to be solved in the future development of photonic crystal solar cells.

Two-dimensional dense packing structure can be prepared by selfassembly of monodisperse microspheres, which provides a faster, simpler and controllable way for the introduction of the twodimensional photonic crystal structure of solar cells. Chen et al. [76] prepared two-dimensional porous perovskite film (IOP)by template-assisted spin-coating method (Fig. 17). The unique structure of two-dimensional porous thin films restricted the growth of perovskite crystals and changed the intrinsic electronic state of perovskites, which causes the corresponding absorption peaks and fluorescence emission spectra is a shift [6]. The highest conversion efficiency of the color PSC was obtained with a maximum conversion efficiency of $11.2 \%$ by using $500 \mathrm{~nm}$ and $1000 \mathrm{~nm}$ two-dimensional porous $\mathrm{MAPbI}_{3}$ thin films as the absorbent layer of the cell. At the same time, the two-dimensional porous perovskite film with the aperture is $500 \mathrm{~nm}, 1000 \mathrm{~nm}$ and $2000 \mathrm{~nm}$ was prepared by four kinds of perovskite $\mathrm{MAPbBr}_{3}, \mathrm{MAPb}$ $\mathrm{Br}_{1.5} \mathrm{I}_{1.5}, \mathrm{MA}_{0.5} \mathrm{FA}_{0.5} \mathrm{PbI}_{3}$ and $\mathrm{FAPbI}_{3}$. This method has certain flexibility and universality [6].

Snaith et al. $[77,78]$ obtained honeycomb scaffold (HC) by template method. They then spin-coated perovskite precursors into the pores of the scaffolds. The porosity of HC thin film and the concentration of perovskite precursor solution can limit the crystalline region of perovskite and then form a homogeneous perovskite film. As shown in Fig. 18a and b. The introduction of photonic crystal structure enhances the open circuit voltage and filling factor of the cell, which keeps the photoelectric conversion efficiency and the transparency of the device at $9.5 \%$ and $37 \%$, respectively. As shown in Fig. 18c.

The "moth eye" structure was used as a template. Park et al. [79] obtained a moth-eye $\mathrm{TiO}_{2}$ mesoporous layer by shaping and nanoimprinting techniques. As shown in Fig. 19. Compared with ordinary $\mathrm{TiO}_{2}$ mesoporous layer, the photoelectric conversion efficiency of PSC increased from $15.31 \%$ to 17.48 with the introduction of moth-eye $\mathrm{TiO}_{2}$.

There are many methods to prepare silicon nanowires, including chemical vapor deposition, hydrothermal method and laser ablation method. The single crystal silicon synthesized by these methods has good linearity and can be effectively regulated in size, but it is not suitable for preparing silicon wires in a large area, which is also a problem to be solved in the future development of photonic crystal solar cells.

Increasing array absorption per unit area in a limited array of silicon nanowires is also an idea to improve cell efficiency. In dielectric cylindrical photonic crystals, in order to improve efficiency, many researchers treat nanowires as a core-shell structure. Yang's group [80] wrapped a layer of $\mathrm{Cu}_{2} \mathrm{~S}$ on a single $\mathrm{CdS}$ nanowire to form a core-shell solar cell. Its absorption efficiency is higher in the wavelength range of $300-800 \mathrm{~nm}$, and the peak appears near the wavelength of $500 \mathrm{~nm}$. The cell efficiency reaches $5.4 \%$. Hokkaido University and Honda Group, a Japanese manufacturer, have developed nanowire solar cells with core-shell structure of indium phosphide, which have a conversion efficiency of up to $12.3 \%$ [39]. In summary, nanowires are treated in two ways: anti-reflective layer was deposited on the surface of silicon wire and oxides are added to induce light scattering.

Fan et al. [81] enhance the absorptivity of PSC by using PDMS nanocone array microstructure. Fig. 20 shows the schematic diagrams of perovskite solar cell and nanocone film preparation. In this way, the
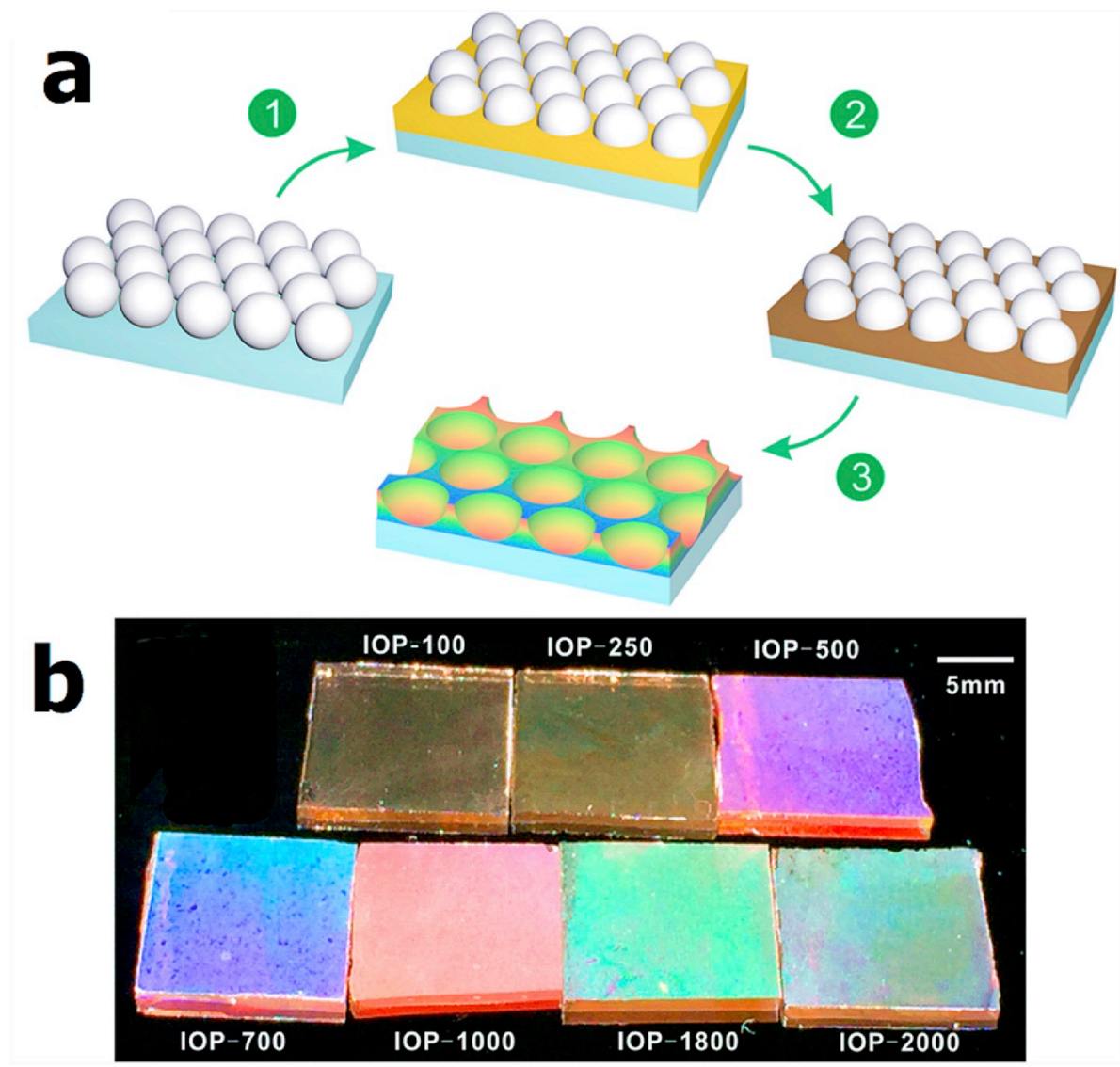

Fig. 17. (a) The schematic diagram of a 2D IOP film preparation, (b)The digital photo of various 2D IO MAPbI3 photonic films on glass substrates placed on a silicon wafer under AM1.5 illumination [76]. (For interpretation of the references to color in this figure legend, the reader is referred to the Web version of this article.) 

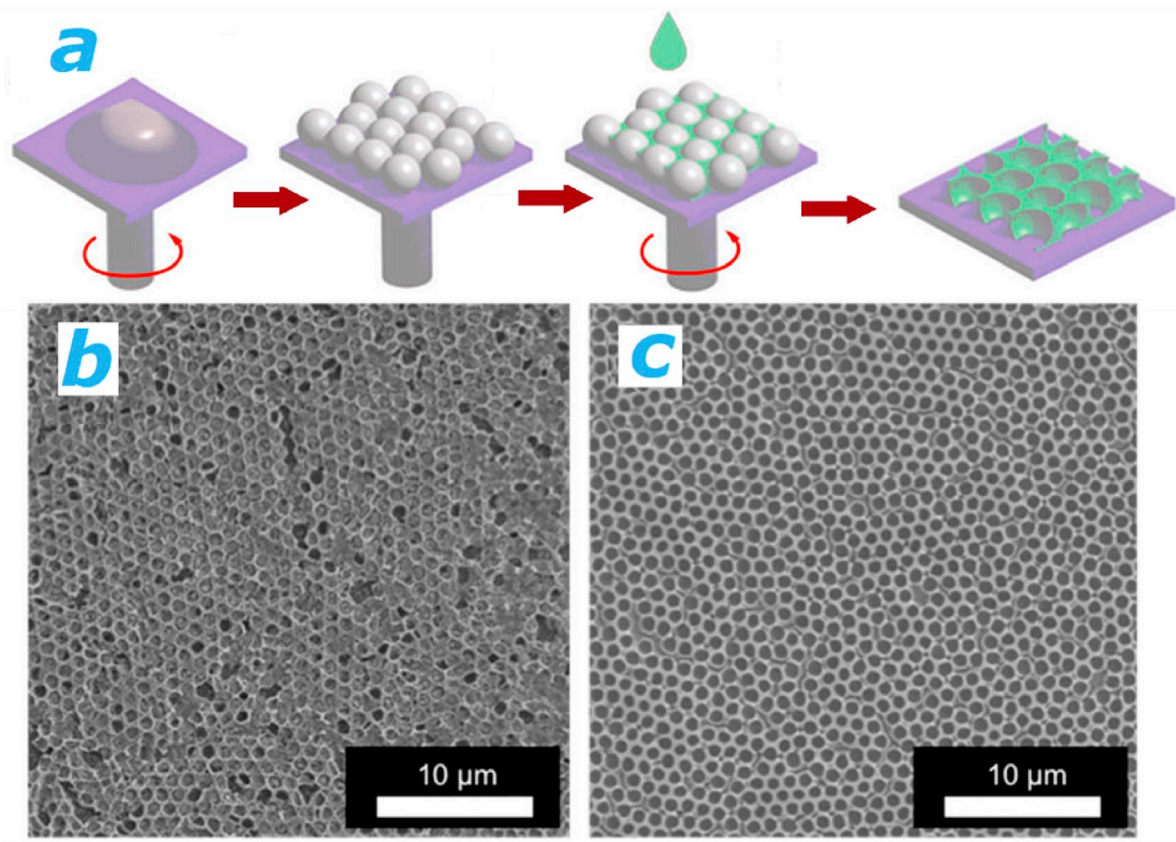

Fig. 18. (a) Fabrication steps for patterned oxide scaffolds, $\mathrm{SEM}$ images showing perovskite film formations within $\mathrm{TiO}_{2}$ (b) and $\mathrm{SiO}_{2}$ (c) honeycomb scaffolds [77].
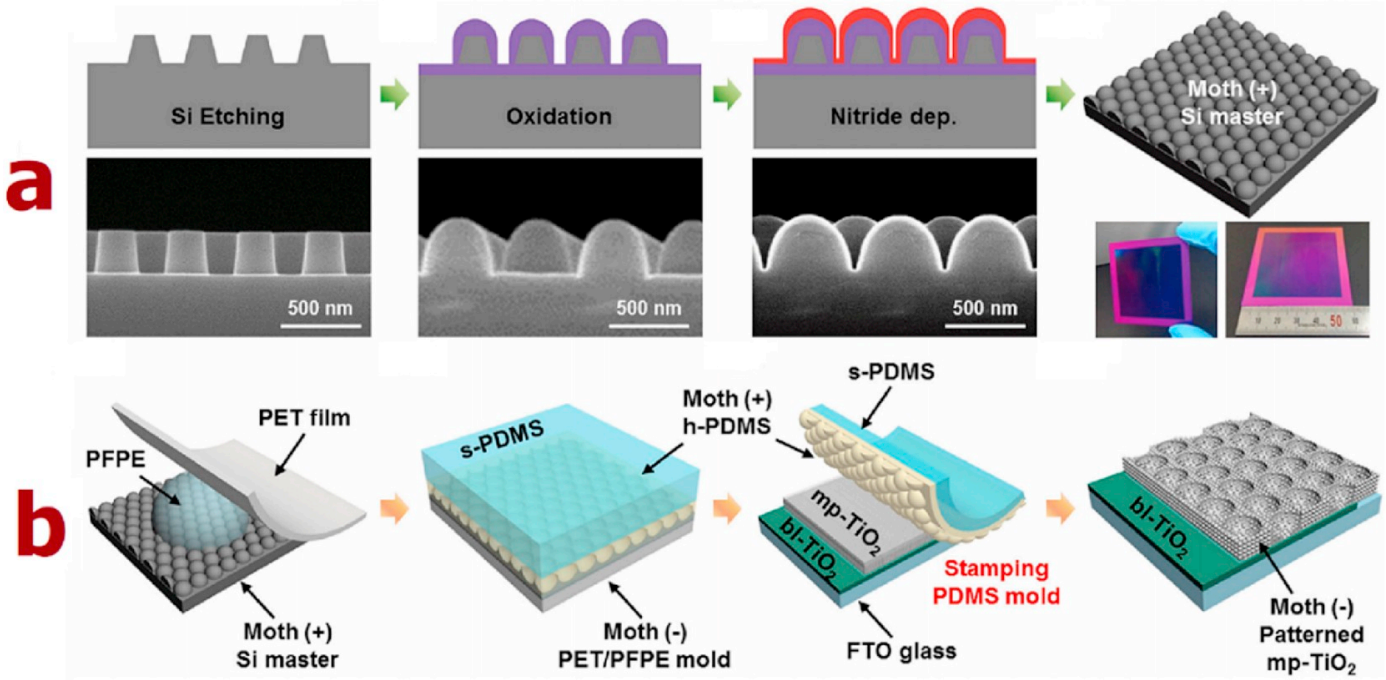

Fig. 19. The schematic diagram of "moth-eye"-type two-dimensional photonic crystal $\mathrm{TiO}_{2}$ preparation [79].

external quantum efficiency of the flexible PSC is increased, and the photoelectric conversion efficiency is increased from $12.06 \%$ to $13.14 \%$.
At the same time, the super hydrophobicity of PDMS microstructures can insulate the water and make the surface of the cell have the

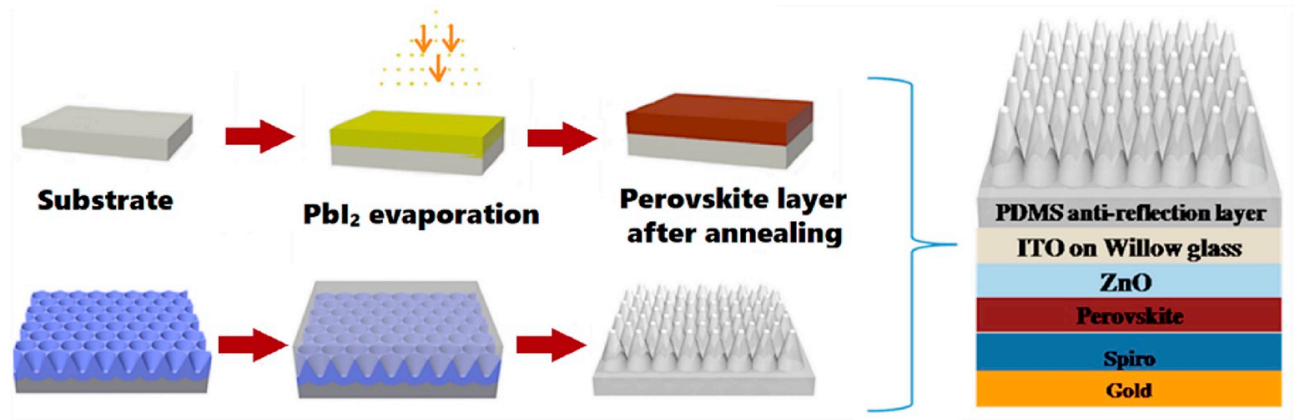

Fig. 20. Schematic diagrams of perovskite solar cell and nanocone film preparation [81]. 
self-cleaning ability [6], which can prolong the service life of PSC. After 200 bending tests, the cell can still maintain a stable photoelectric performance.

Wu Zhenhua et al. [82] designed an amorphous silicon thin film solar cell back reflector consisting of a one-dimensional photonic crystal and a two-layer two-dimensional photonic crystal using a-Si:H and $\mathrm{SiO}_{2}$. Fig. 21 shows the schematic of amorphous silicon thin-film solar cells with 1D and double-layered 2D photonic crystal back reflector. They used the finite-difference time-domain method to simulate the reflectivity and transmittance of the backreflector in the wavelength range of incident light of $300-1100 \mathrm{~nm}$, calculate the short-circuit current density of amorphous silicon solar cell under different structure parameters, and conduct comparative analysis to obtain the best backreflector structure. The results show that the designed solar cell back reflector can effectively extend the transmission path of incident light in the solar cell absorption layer, help to alleviate the influence of the thickness of the solar cell absorption layer on the absorption efficiency of the solar cell, and improve the absorption efficiency of the incident light. The one-dimensional photonic crystal and the double-layer two-dimensional photonic crystal structure of the back reflector can greatly improve the light-trapping ability of the cell, and increase the short-circuit current density of the amorphous silicon thin film solar cell to $31.96 \mathrm{~mA} / \mathrm{cm}^{2}$. Compared with the amorphous silicon thin film solar cells with $\mathrm{Ag} / \mathrm{ZnO}$ backreflector structure, the short circuit current density is increased by $51.0 \%$.

\subsection{Three-dimensional photonic crystal sensitized solar cells}

Compared with one-dimensional and two-dimensional photonic crystals, three-dimensional photonic crystals have more complex structures and better band gap effect. Solar cells fabricated using a threedimensional photonic crystal structure can greatly improve the efficiency of solar cells due to the increase in photon retention time and average photon distance. Due to the complex structure of threedimensional photonic crystals, ordinary methods for preparing twodimensional and one-dimensional photonic crystals are not suitable for three-dimensional photonic crystals [39]. Three-dimensional photonic crystal preparation methods can be divided into the following: dip pen nanolithography, colloidal microsphere self-assembly, multi-beam coherence, phase grating, grazing angle deposition technology and electron beam ion beam combination, etc. Three-dimensional photonic crystals are mainly used in sensitized solar cells, which are mainly accomplished by self-assembly method. In the process of self-assembly, the basic structural units spontaneously organize or aggregate into a stable structure with regular geometric appearance under the interaction of non-covalent bonds. Liquid electrolyte sensitized solar cells have achieved maximum quantum efficiency (photoelectric conversion) in the spectrum range of about $520 \mathrm{~nm}$, but relatively low efficiency in infrared and near-infrared light capture. In solid-state devices, light capture is generally limited by the thickness of the film, because thick mesoporous materials are difficult to penetrate [39].

In order to solve these problems, three-dimensional polystyrene (PS) colloidal photonic crystals with various FCC structures were selfassembled by horizontal deposition method, and three-dimensional PS colloidal photonic crystals with $495 \mathrm{~nm}$ diameter were obtained. The results show that the structure has a good reflection spectrum in the far infrared region from 1800 to $2000 \mathrm{~nm}$. PS colloidal crystals with a diameter of $790 \mathrm{~nm}$ have good reflectance spectra in the near infrared region of $950-1150 \mathrm{~nm}$ [39].

Three-dimensional photonic crystals could also be used to make electrodes to further improve the efficiency of solar cells. Shan Tiyu [39] prepared a composite photocathode of CdSe nanoclusters and photonic crystals with anti-opal structure of $\mathrm{TiO}_{2}$. Photonic crystals with anti-opal structure of $\mathrm{TiO}_{2}$ are prepared by liquid phase deposition using $225 \mathrm{~nm}$ polystyrene micro-globular opal as template. The test results show that it has a large photoelectric conversion efficiency in the visible wavelength range of $400-700 \mathrm{~nm}$, which is 2.5 times of $\mathrm{TiO}_{2}$ thin film composite electrode.

In 2003, Mallouk et al. [6] used 3D $\mathrm{TIiO}_{2} \mathrm{IOPC}$ for liquid dye-sensitized solar cells for the first time, and the photocurrent density was increased by $26 \%$. Since then, 3D photonic crystals have been widely used in sensitized solar cell (DSSC) [6]. The effect of different position modification of photonic crystal on the cell was studied [6].

(a) The sensitized $\mathrm{TiO}_{2} \mathrm{IOPC}$ is used as a photoanode in a solar cell. Photonic crystals are able to reflect photons within the band gap range of photons and reduce the absorption of photons within that frequency range by sensitizer. Therefore, in the photonic crystal reflectance spectrum (black line), the spectral diagram (blue line) of the enhancement factor $\gamma$ of the monochromatic light conversion efficiency corresponding to the band gap range reaches the minimum value (Fig. 22a). Thus, the simple photonic crystal structure is not suitable for application in sensitized solar cells [83].

(b) The combination of $\mathrm{nc}-\mathrm{TiO}_{2}$ layer and $\mathrm{TiO}_{2} \mathrm{PC}$ has two structures. The first structure is that the $\mathrm{nc}-\mathrm{TiO}_{2}$ layer is deposited on the transparent conductive substrate of the photoanode. The other is to reverse the order of $n c-\mathrm{TiO}_{2}$ layer and $\mathrm{PC}$ layer. $\mathrm{The} \mathrm{TiO}_{2} \mathrm{PC}$ is deposited on the conductive substrate first.

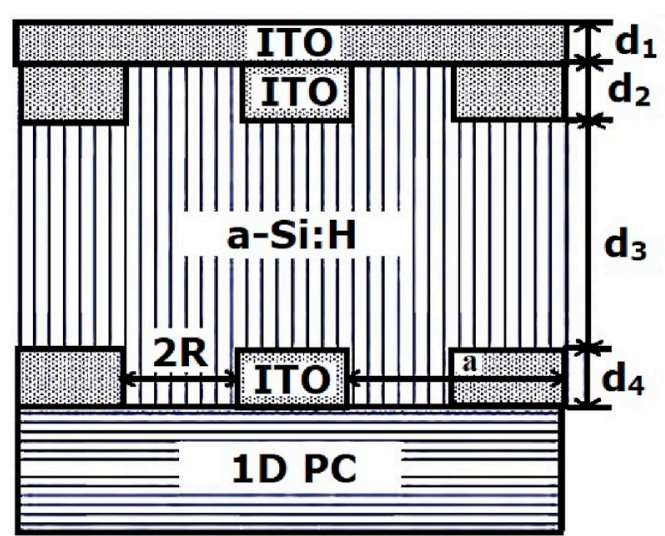

(a) Schematic of solar cell

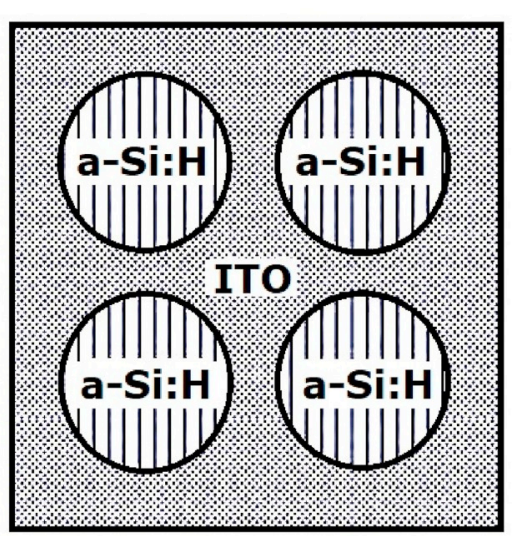

(b) Top view of 2D PC

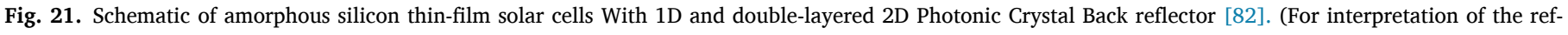
erences to color in this figure legend, the reader is referred to the Web version of this article.) 

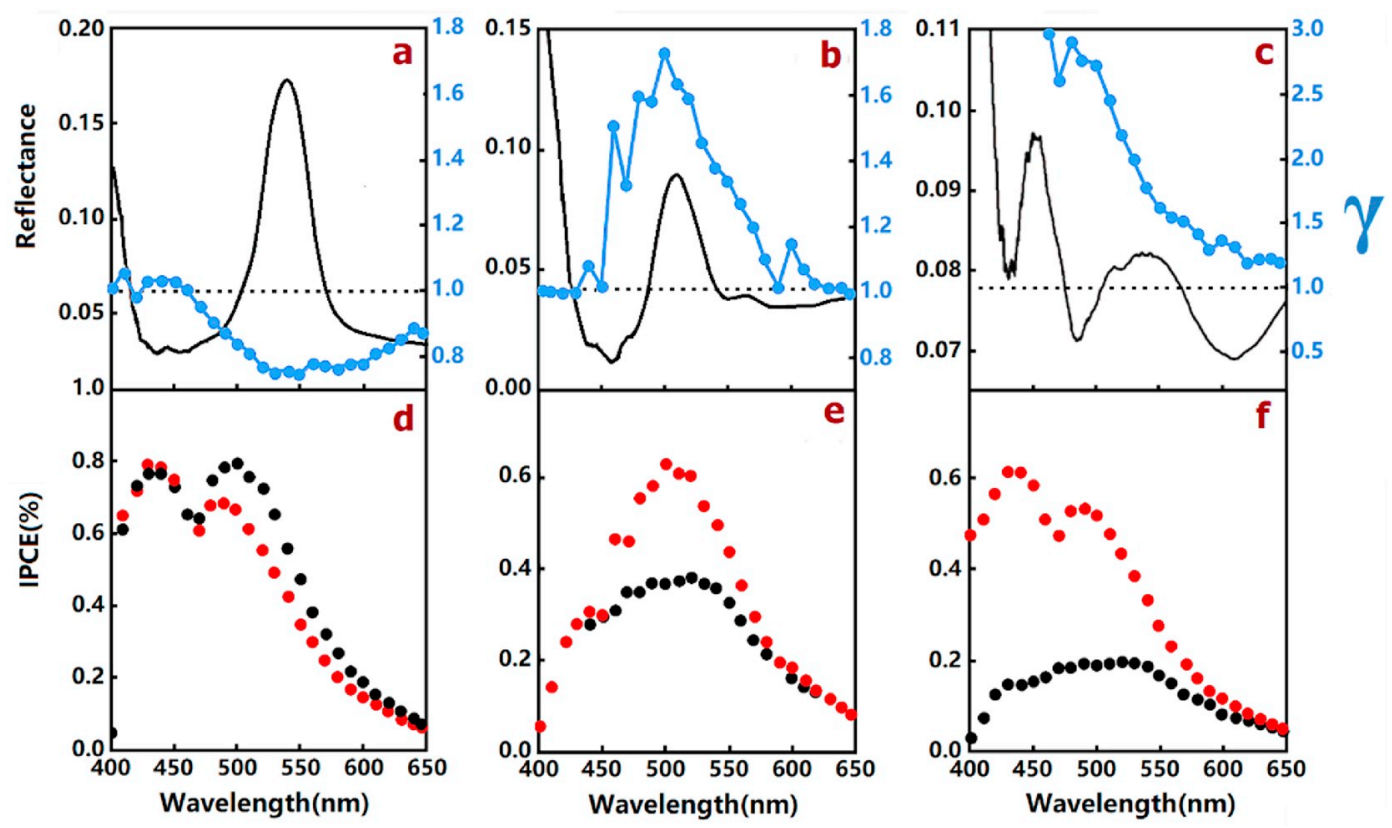

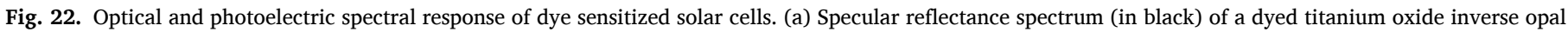

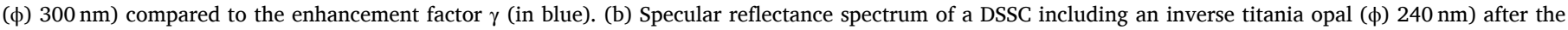

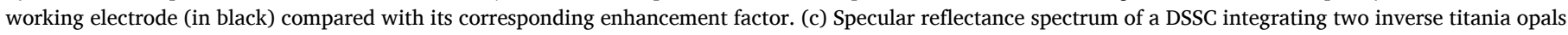

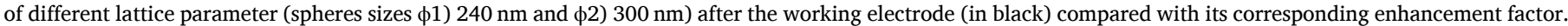

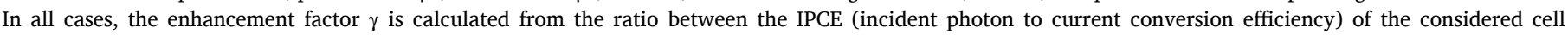

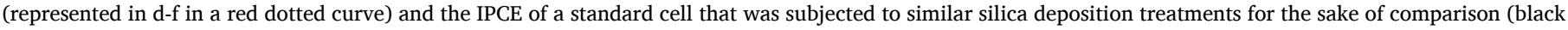
dotted curves) [83]. (For interpretation of the references to color in this figure legend, the reader is referred to the Web version of this article.)

(c) In addition to changing the refractive index difference of the material in the PC film, there are other ways to expand the spectral response range of the resonant mode. Miguez et al. [83] widen the band gap of photons by connecting two IOPC films with $240 \mathrm{~nm}$ and $300 \mathrm{~nm}$ apertures. The corresponding optoelectronic properties are shown in Fig. 22c and f. The red curve is the IPCE spectrum corresponding to the three-layer photoanode DSSC. Compared with the red curve in Fig. 22e, two kinds of IOPC thin films in a series can effectively widen the spectral response range of resonance mode, and the corresponding conversion efficiency $\eta$ is $0.625 \%$. Compared with the Gratzel cell, also called a reference cell, the conversion efficiency was increased by $12.4 \%$.

The structure of photoanode is used by Miguez et al. [6]. The incident light is illuminated from the opposite electrode. They found the reason for increasing the efficiency of photonic crystals DSSC in addition to the "slow photon" effect to enhanced absorbance [6] and the photons are confined to the nc- $\mathrm{TiO}_{2}$ layer [6]. Due to the photonic band gap characteristics of photonic crystals, there are multiple resonance modes at the interface between photonic crystal and $\mathrm{nc}-\mathrm{TiO}_{2}$ layer. It confines the photons in the band gap range of the photons to the absorption layer of nc- $\mathrm{TiO}_{2}$ [6] and makes the photons interact fully with the dye molecules, which can improve the efficiency of optical enrichment and photoelectric conversion of DSSC (Fig. 22b and e). When the nc- $\mathrm{TiO}_{2}$ layer is combined with the photonic crystal, the corresponding IPCE is obviously increased at the photonic band gap [83]. The result Shows that the intensity of resonance mode, the position of band gap and the transparency of the cell are related to the thickness of $\mathrm{nc}^{-\mathrm{TiO}_{2}}$ layer and the scattering intensity of photonic crystal. In addition, the results show that the optical localization is independent of the morphology of photonic crystals and whether the photonic crystals are sensitized or not. Photonic crystals can be made of non-conductor materials, or three-dimensional IOPC can be replaced by one-dimensional photonic crystals.

Guldin, S. et al. [84] co-deposited block copolymers and $\mathrm{TiO}_{2}$ nanoparticles of $1-4 \mathrm{~nm}$ in diameter on transparent conductive substrates to form mesoporous layers by spin-coating method. Then, the PS microspheres as templates, they filled amorphous $\mathrm{TIO}_{2}$ into gaps in opal photonic crystals by atmospheric pressure chemical vapor deposition (APCVD). Finally, the polymer in the mesoporous layer and the PS microsphere template in the photonic crystal layer are removed by sintering at high temperature and the porous double-layer photoanode electrode was formed (Fig. 23). Compared with the bilayer electrode prepared by Mallouk et al. [85], this method not only makes the interface between the two layers more smooth but also maintains the integrity of the pore structure in the absorption layer and the connectivity of the pores between the bilayer cells through the filling of the copolymer (Fig. 24). It can make the electrolyte fully permeate, which

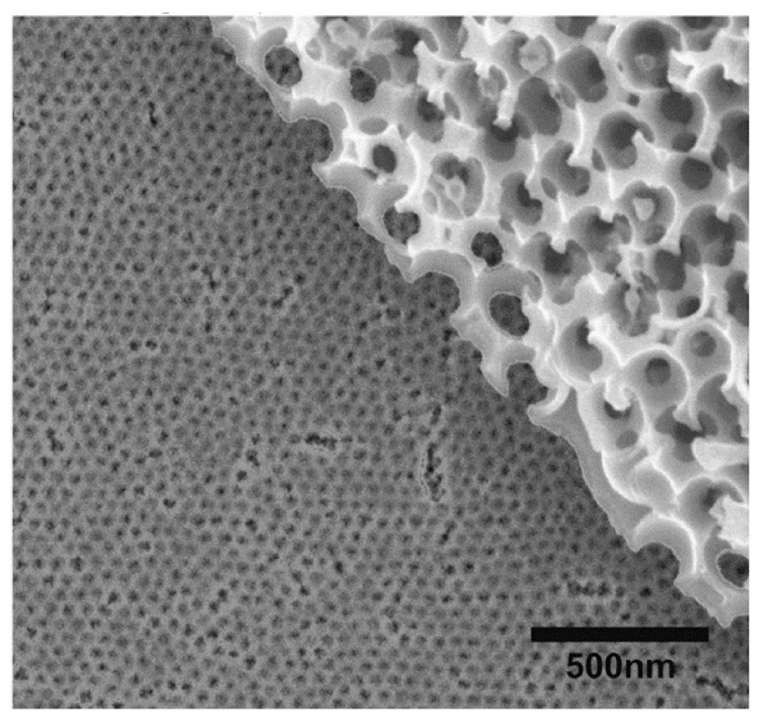

Fig. 23. High-resolution SEM showing complete pore connectivity between mesopores and micropores [84]. 
can improve the dye sensitization effect and enhance the charge fluidity. At the same time, the short circuit current density (JSC) and external quantum efficiency (EQE) of DSSC can be effectively enhanced by using the resonant mode between PC and absorption layer.

In quantum dots sensitized solar cell (QDSSC), quantum dots are equivalent to dye molecules in DSSC and need to be implanted into nanoscale semiconductor materials before they are used as photoanodes. But unlike dye molecules, quantum dots are only a few nanometers in three dimensions. The aperture of the one-dimensional photonic crystal is $10 \mathrm{~nm}-15 \mathrm{~nm}$, while that of three-dimensional IOPC is larger. Moreover, because quantum dots have multiple exciton effects, it is unnecessary to design semiconductor materials with larger specific surface area. So, IOPC has become a common photonic crystal structure in QDSSC. Photonic crystals with an inverse opal structure can effectively reduce the charge recombination rate and increase the open circuit voltage of QDSSC. Therefore, IOPC has become a common photonic crystal structure in QDSSC. Photonic crystals with an inverse opal structure can effectively reduce the charge recombination rate and increase the open circuit voltage of QDSSC. Inverse opal photonic crystal is a kind of material with three-dimensional ordered macroporous structure. Multiple scattering of light inside the material can increase the contact time between the material and the light, thus improving the absorption ability of the material to the light. Because $\mathrm{TiO}_{2}$ porous film has larger pore diameter, orderly structure, and fewer surface defects, the recombination probability of electrons in the process of transmission is reduced, thereby obtaining a relatively high open circuit voltage.

Toyoda et al. [6] prepared two $\mathrm{TiO}_{2}$ IOPCs by using PS microspheres of $309 \mathrm{~nm}$ and $394 \mathrm{~nm}$ in diameter as templates and obtained QDSSCs with a conversion efficiency of $2.7 \%$ by filling $\mathrm{Cd} / \mathrm{Se}$ precursors and electrolytes into IOPC pores. Compared with photonic crystals with smaller aperture size, macroporous photonic crystals have a better filling effect and higher PCE. Meng et al. [6] prepared $\mathrm{SnO}_{2}$ IOPC by scraper method and liquid deposition method. They introduced $\mathrm{SnO}_{2} \mathrm{IOPC}$ into CDS/Cd se co-sensitized QDSSC and obtained a relatively high open circuit voltage of $700 \mathrm{mV}$. Compared with mesoporous $\mathrm{SnO}_{2}$ photoanode, $\mathrm{SnO}_{2}$ IOPC photoanode can effectively reduce exciton recombination rate and increase the open circuit voltage and filling factor. Toyoda et al. [6] used $\mathrm{TiO}_{2}$ IOPC as the photoanode of Cd Se QDSSC. Compared with the mesoporous $\mathrm{TIO}_{2}$ photoanode, the open circuit voltage of the cell is also significantly increased. Halaoui et al. [6] studied the effect of the enhancement effect of photonic bandgap on QDSSC. They matched Cd S QD with $410 \mathrm{~nm}$ at the edge of the absorption peak with $\mathrm{TiO}_{2} \mathrm{IOPC}$ with a photonic band gap of $390 \mathrm{~nm}$ and $450 \mathrm{~nm}$, respectively. The results were different from those of DSSC. The enhancement factor for the conversion efficiency of the photonic band gap blue band to QDSSC is 4.7, which is significantly higher than that of the red band edge enhancement factor 1.4-1.8. The scattering effect of $\mathrm{TiO}_{2}$ thin films with disordered structure can also enhance the photoelectric conversion efficiency of QDSSC. This film can increase the scattering of light, so that the incident light is deflected and absorbed by the dye repeatedly to increase the absorption of light, without increasing the path of photogenerated electron transmission.

Toyoda et al. [6] proposed that the morphology of $\mathrm{TiO}_{2}$ photonic crystal photoanode has an important effect on the photoelectric conversion efficiency of QDSSC. Due to the large proportion of electrons injected from $\mathrm{QD}$ to $\mathrm{TiO}_{2}$, the quasi-Fermi level of semiconductor materials increases, and the recombination rate of excitons in $\mathrm{TiO}_{2}$ IOPC photoanode is decreased. IOPC photoanode can increase the open circuit voltage of QDSSC. However, the short circuit current density of $\mathrm{TiO}_{2}$ IOPC QDSSC is generally low. This problem can be solved by increasing the thickness and assembly quality of photonic crystals, reducing the band gap width of photonic crystals and combining two kinds of quantum dots. In addition to the reverse opal structure, $\mathrm{TiO}_{2}$ Nanotubes $\left(\mathrm{TiO}_{2}\right.$ NT) with large pores will also be the key to the development of the next generation of efficient QDSSC.

Kanatzidis et al. [86] used p-type inorganic perovskite $\mathrm{CsSn}-\mathrm{I}_{3}$ as solid hole transport material (HTM) instead of liquid electrolyte in dye DSSC to form all-solid-state dye-sensitized solar cells (solid-state DSCs, ss DSCs). Different from the liquid electrolyte, $\mathrm{CsSn}-\mathrm{I}_{3}$ perovskite has long-term stability and can be calculated theoretically based on the electronic structure. Therefore, it can further improve the photovoltaic characteristics of DSSC. The advantages of p-type inorganic perovskite $\mathrm{CsSnI}_{3}$ are $1.3 \mathrm{eV}$ direct band gap, high hole mobility and suitable conduction band position $(3.62 \mathrm{eV})$. After doping $\mathrm{F}$ and $\mathrm{SnF}_{2}$, the

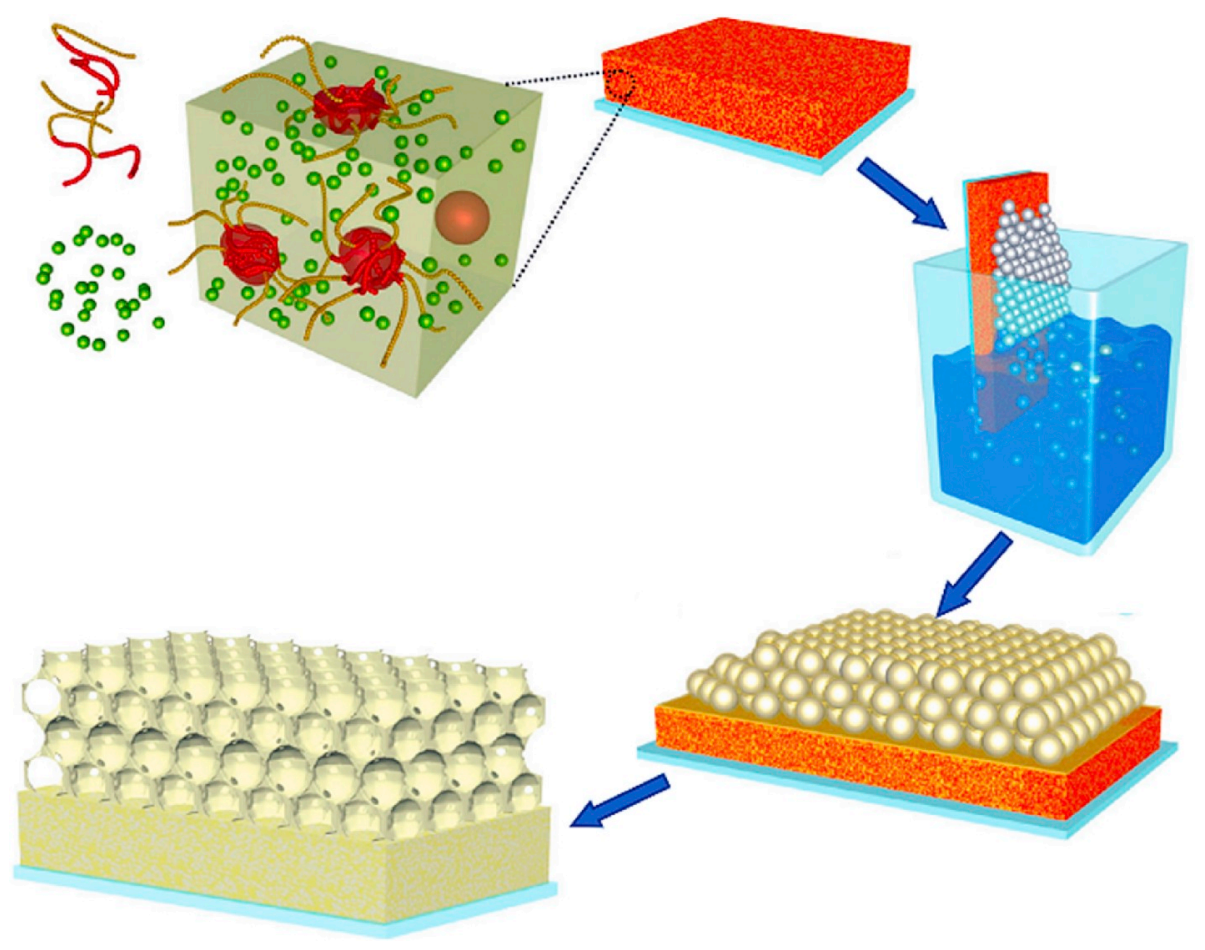

Fig. 24. Schematic of double layer assembly [84]. 
photoelectric conversion efficiency of $9.8 \%$ can be achieved by using N719 as a sensitizer. The efficiency can be further improved to $10.2 \%$ by introducing the double layer $\mathrm{ZnO}$ IOPC pair electrode, which far exceeds the performance of the Gratzel cell. Yang et al. [87] introduced $\mathrm{TiO}_{2}$ IOPC as an electron transport layer (IOP-ETL). It has traditional dense and scaffold functions (Fig. 25). The excellent light control ability of IOP-ETL improves the efficiency of PSC, which increases the short-circuit current density of PSC (Fig. 26). In addition, the addition of $\mathrm{Ti}\left(\mathrm{SO}_{4}\right)_{2}$ coating on the substrate of IOT-ETL film can effectively inhibit the recombination of excitons and enhance the open circuit voltage of PSC (Fig. 27). Finally, the photoelectric conversion efficiency of PSC is $13.11 \%$. The introduction of the $\mathrm{TiO}_{2}$ electron transport layer with multifunctional inverse opal structure can not only improve the photoelectric conversion efficiency of PSC but also reduce the manufacturing cost.

Light trapping is one of the key technologies to improve the light absorption and efficiency of solar cells. He Xiaojin et al. [88] designed a silicon thin film solar cell with different back reflection trapping structures (Fig. 28). The back reflection trapping structures are metal aluminum, metal aluminum grating, opal structure three-dimensional photonic crystal (3D PC) and metal grating laminated structure.

The thickness of the silicon material of the solar cell absorbing layer corresponding to various trapping structures is set to $4 \mu \mathrm{m}$, the thickness of the anti-reflective coating (AR) is $150 \mathrm{~nm}$, and the refractive index is 1.87. The metal aluminum back reflector solar cell model in Fig. 28a is used as a reference cell. The metal aluminum grating structure in Fig. 28b is formed by periodically arranging nano columns with a rectangular cross section. The height $(\mathrm{H})$ of the cross section of the nanocolumn ranges from $50 \mathrm{~nm}$ to $500 \mathrm{~nm}$, the duty cycle (D a/b) ranges from 0.1 to 0.9 , and the distance (b) between the two adjacent nanocolumns, i.e., the grating period (P) ranges from $100 \mathrm{~nm}$ to $1000 \mathrm{~nm}$. In Fig. 28 (c), the inverse opal structure 3DPC is an air dielectric sphere with several layers of dielectric constant embedded in the silica material. The radius $\mathrm{R}$ of the sphere increases from $50 \mathrm{~nm}$ to $500 \mathrm{~nm}$ with a step length of $50 \mathrm{~nm}$, and the number of layers L changes from 1 to 10. In Fig. 28d, photonic crystals and metal gratings are stacked as the back reflection structure of the cell. They simulated the influence of back reflection of silicon thin film solar cells on the light absorption of solar cells by changing the important structural parameters of metal gratings, photonic crystals, photonic crystals and metal grating stacks. The EFTD-based MEEP software package is used to strictly solve Maxwell's equations to simulate the light absorption of solar cells.

In summary, the results show that metal grating back reflection mainly enhances the solar cell's absorption of light in the infrared wavelength range. When the period of the metal grating is $700 \mathrm{~nm}$, the height is $100 \mathrm{~nm}$, and the duty ratio is 0.7 , the average absorption rate of the solar cell in the $750-1200 \mathrm{~nm}$ band is $45.4 \%$ higher than that of the metal aluminum back reflector reference cell. The inverse opal structure 3D PC used for the back reflection structure of silicon thin film solar cells has the optimum structure parameters: the radius of the air medium sphere is $150 \mathrm{~nm}$ and the number of layers is 2 . Compared with the metal aluminum back reflector, this 3D PC back reflection structure increases the light absorption of the silicon thin film solar cell by an average of $34.8 \%$ in the range of $750-1200 \mathrm{~nm}$. The laminated back-reflective structure solar cell has the best light absorption enhancement effect on the whole range of $300-1200 \mathrm{~nm}$, and the light absorption of the metal aluminum back reflection structure is increased by $32 \%$ on average, which is better than the effect of using metal grating or photonic crystal alone. Due to the good reflection characteristics of the metal grating and the photonic crystal, the transmitted light is reflected back to the absorption layer of the solar cell for secondary or multiple absorption, which enhances the absorption efficiency of the silicon thin film solar cell $[88,89]$.

\section{Conclusion}

Compared with traditional optical enrichment, photonic crystals have many advantages due to their unique optical properties. The introduction of photonic crystals can be divided into two types, one is placed inside the cell as the electron transport layer, the other is placed on the outer side of the cell opposite electrode as the back mirror. In this paper, the preparation method of photonic crystal is introduced, and the application of photonic crystal in solar cell is studied, in addition, the application of photonic crystal solar cell in the plateau area with abundant light resources is proposed. The combination of photonic crystal solar cells and biogas can provide electricity and raw materials for the development of animal husbandry, which solves environmental pollution and improves economic benefits.

In silicon solar cells, photonic crystals are usually used as back

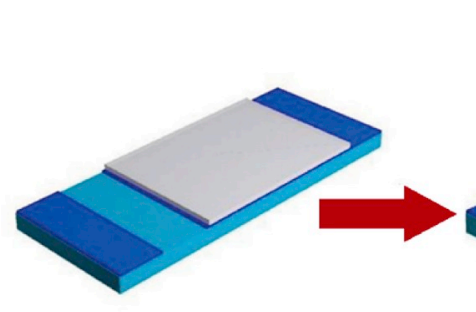

(1) $\mathrm{Ti}\left(\mathrm{SO}_{4}\right)_{2}$ coating

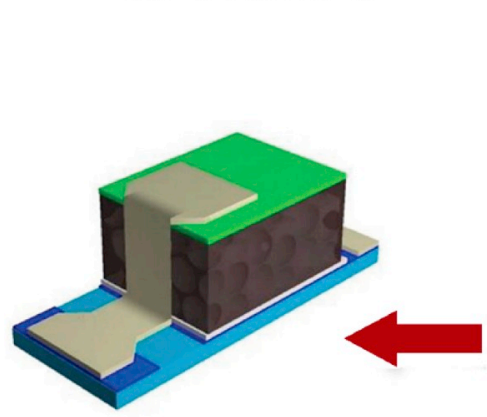

(6) Ag coating

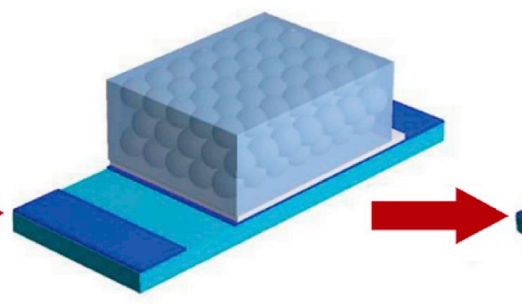

(2) $\mathrm{Ti}\left(\mathrm{SO}_{4}\right)_{2}+\mathrm{PS}$ coating

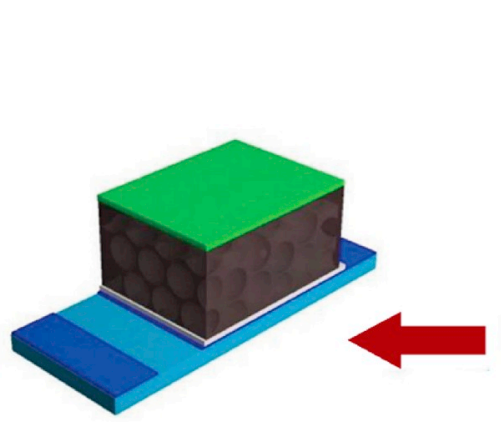

(5) HTM coating

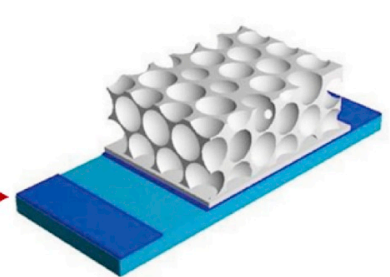

(3) Sintering

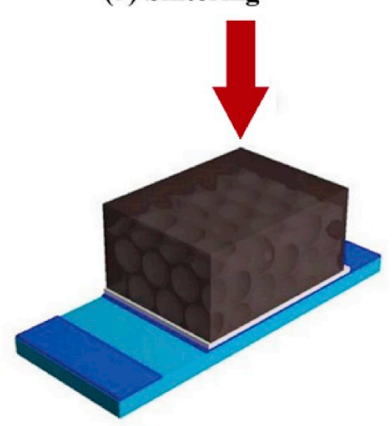

(4) $\mathrm{CH}_{3} \mathrm{NH}_{3} \mathrm{PbI}_{3}$ coating

Fig. 25. Fabrication procedure of the inverse opal-like $\mathrm{TiO}_{2}$ electron transport layer based perovskite solar cells [87]. 


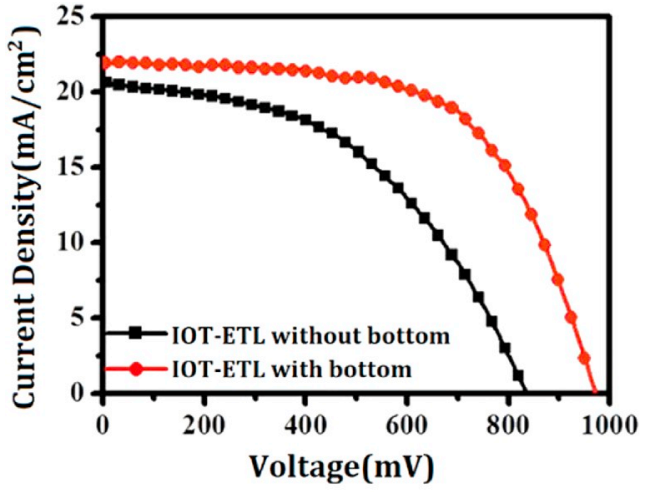

(a)

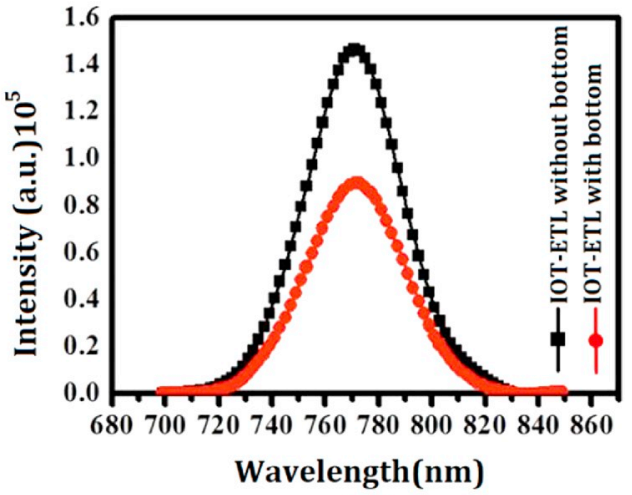

(b)

Fig. 26. J-V curves for perovskite solar cells based on IOT-ETL film with (red circle) and without (black cube) bottom, measured under a simulated AM $1.5 \mathrm{G}$ solar irradiation, (b) room temperature photoluminescence (PL) spectrum of the perovskite coated IOT-ETL film with (red cycle) and without (black cube) bottom (excitation at $600 \mathrm{~nm}$ ) [87]. (For interpretation of the references to color in this figure legend, the reader is referred to the Web version of this article.)
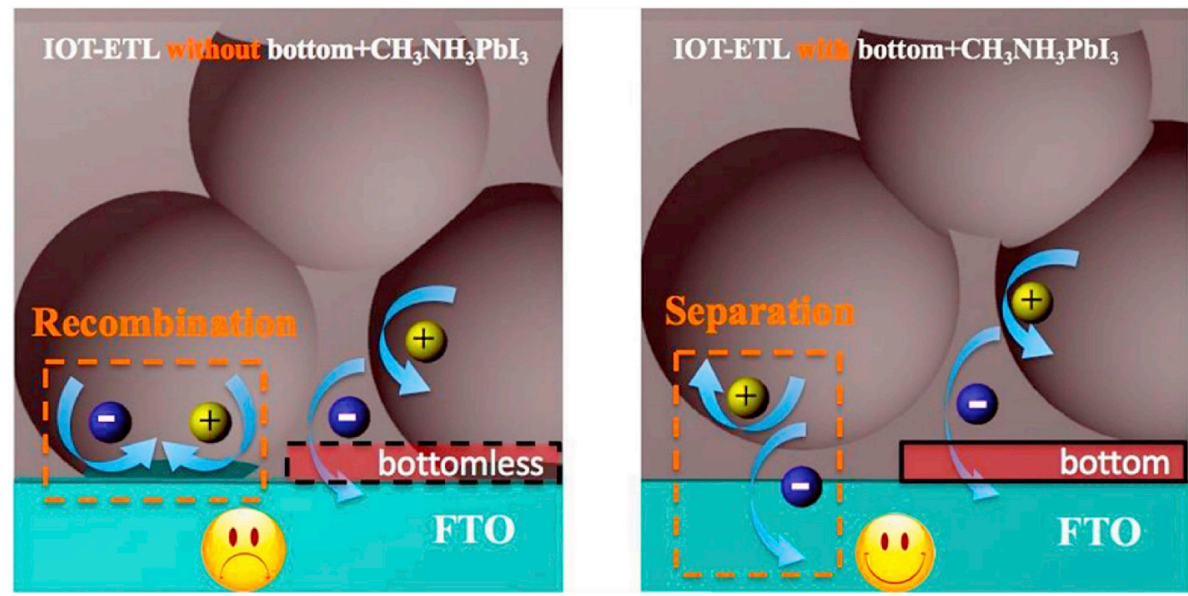

Fig. 27. Schematic illustrating the charge transfer and recombination in the perovskite coated IOT-ETL film without (left) and with (right) bottom [87].

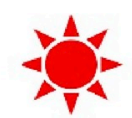

(a)

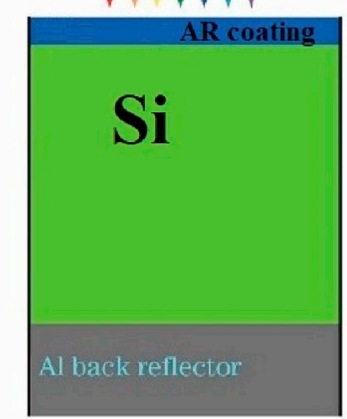

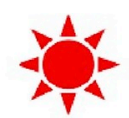

(b)

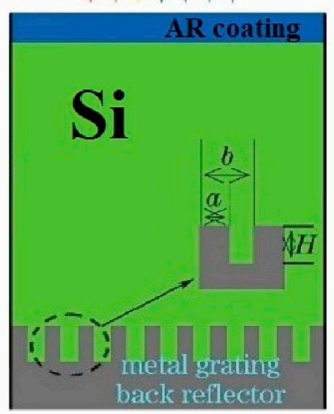

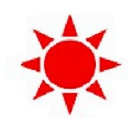

(c) $\downarrow / W$

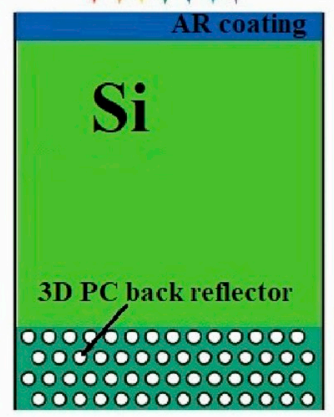

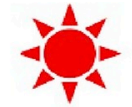

(d) $\downarrow / \| W$

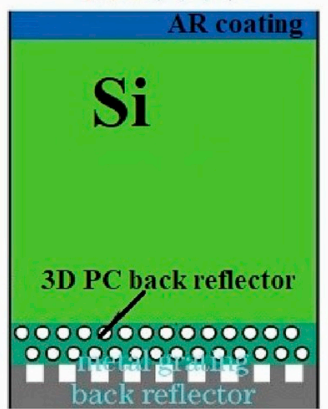

Fig. 28. Schematic diagram of a solar cell model with different back reflection structures. (a) metal back reflection; (b) metal grating back reflection; (c) photonic crystal back reflection; (d) Photonic crystal metal grating back reflection [88].

mirrors, and their bandgap is designed to reflect incident light at different wavelengths. Photonic crystals with a band gap in infrared range are more favorable to improve the performance of silicon solar cells. At the same time, the selection of photonic crystal materials is more extensive. The introduction of photonic crystals can effectively reduce the device thickness and reduce the fabrication cost.

Photonic crystals play a variety of roles in sensitized solar cells. They can be used not only to enhance photoelectric conversion efficiency but 
also as a support layer and scattering layer. One-dimensional photonic crystals, two-dimensional photonic crystals, and three-dimensional photonic crystals have their unique advantages and disadvantages. Due to different pore sizes, two-dimensional and three-dimensional inverse opal photonic crystals are more suitable for QDS SCS than onedimensional photonic crystals. However, compared with 3D photonic crystals, one-dimensional photonic crystals have the advantages of better charge transport, lower exciton recombination rate and higher transparency in DSSC. On the other hand, compared with the onedimensional and three-dimensional photonic crystal structures, the two-dimensional nanotube arrays have the advantages of high controllability, photogenerated electrons can be transferred along the long axis of the tube wall, and the recombination of excitons at the intergranular interface is reduced.

Therefore, for the design of different types of photonic crystal solar cells, researchers should fully understand the photonic crystal light control performance and choose the appropriate photonic crystal structure and illumination direction. At present, photonic crystal structures are widely used in DSSC and QDSSC, but relatively few in the field of PSC. It is pointed out that although photonic crystals have many excellent optical control properties, it is difficult to meet the thickness requirements of PSC due to the limitations of preparation technology and structure of photonic crystals. At present, the photoelectric conversion efficiency of photonic crystal PSC is generally low. Therefore, develop new technology for preparing the large area and high quality ultra-thin photonic crystals, make a profound study of photonic crystal light control mechanism, design new structures, and explore new functions of photonic crystals will become the future development direction of photonic crystal solar cells.

\section{References}

[1] Tseng FM, Chu YW, Peng YN. Using patent data to analyze the development of the next generation of solar cells. In: Management of Engineering \& Technology, 2009 PICMET 2009. Portland International Conference on. IEEE; 2016. p. 3064-72.

[2] Chen JKC, Pham VK, Lin FC. Studying the patent of technology development on dye sensitized solar cell. In: Technology Management in the IT-Driven Services (PICMET), 2013 Proceedings of PICMET . IEEE; 2016. p. 985-96.

[3] KUZMA-FILIPEK IJ, DUERINCKX F, KERSCHAVER EV. Chirped porous silicon reflectors for thin-film epitaxial silicon solar cells. J Appl Phys 2008;104(7): 073529.

[4] Mutitu JG, Shi S, Barnett A. Angular selective light filter based on photonic crystals for photovoltaic applications. IEEE Photonics J 2016;2(3):490-9.

[5] Islam MS, Hoq M, Abu SHM. Challenges and prospects of cost-effective Si-based solar cells fabrication in Bangladesh. In: Electrical Engineering and Information \& Communication Technology, 2014 International Conference on. IEEE; 2014. p. 1-6.

[6] Wu Zhenhua. Research on high efficiency back reflector of solar cells based on photonic crystal. Guilin University of Electronic Technology; 2016.

[7] Zhao Cong, Ma Ying, Wang Yang, Zhou Xue, Li Huizeng, Li Mingzhu, Song Yanlin. Research progress of photonic crystal solar cells. Acta Chim Sin 2018;76:9-21.

[8] Minemoto T, Murata M. Impact of work function of back contact of perovskite solar cells without hole transport material analyzed by device simulation. Curr Appl Phys 2014;14(11):1428-33.

[9] Le KQ, John S. Synergistic plasmonic and photonic crystal light-trapping: architectures for optical up-conversion in thin-film solar cells. Opt Express 2014;22 (S1):A1-12.

[10] Yablonovitch E, Gmitter TJ, Leung KM. Photonic band structure: the face-centeredcubic case employing nonspherical atoms.m. Phys Rev Lett 2016;67(17):2295-8.

[11] Zhang Ling, Liang Liang, Zhang Linli. Study on band gap structure of onedimensional photonic crystals. Acta Photonica Sin 2016;37(9):1815-8.

[12] Lei Li, Liu Guiqiang, Chen Yuanhao. Photonic crystal heterojunction coupled waveguide optical switch. Acta Opt Sin 2013;(1):216-22.

[13] John S. Light trapping and solar energy harvesting with 3D photonic crystals. In: Photonics Conference (IPC), 2012 IEEE. IEEE; 2012. 126-126.

[14] Li Xiujie. Optical properties and application of two-dimensional triangular lattice photonic crystals. Taiyuan University of Technology; 2010.

[15] Wu Zhenhua, Li Simin, Zhang Wentao. Back reflector of solar cells consisting of one-dimensional photonic crystal and double-layered two-dimensional photonic crystal. Acta Photonica Sin 2016;45(2):0223003-1-0220003-5. February.

[16] Leung KM, Liu YF. Photon band structures: the plane-wave method. Phys Rev B Condens Matter 2015;41(14):10188-90.

[17] Chen P, Hou G, Zhang J. Optimal design of one-dimensional photonic crystal back reflectors for thin-film silicon solar cells. J Appl Phys 2014;116(6). 064508064508-8.
[18] Park Y, Jeon H. Double-layer antireflection coating design for semi-infinite onedimensional photonic crystals. J Light Technol 2004;22(8):1987-9.

[19] Wang W, Chi X, Feng Y. Parallel FDTD simulation of photonic crystals and thin-film solar cells. In: Parallel and Distributed Computing, Applications and Technologies (PDCAT), 2012 13th International Conference on. IEEE; 2012. p. 773-6.

[20] Mutitu JG, Shouyuan S, Caihua C. Thin film solar cell design based on photonic crystal and diffractive grating structures. Opt Express 2008;16(19):15238-48.

[21] SONG Mingli, WANG Xiaoping, WANG Lijun, CHEN Haijiang, LIAN Jiqing, KEXiaolong NINGRenmin. Advances in the fabrication and application of photonic crystals. Mater Rep A April 2016;30(Issue 4):22-7 (A).

[22] Wendt JR, Vawter GA, Gourley PI. Nanofabrication of photonic lattice structures in GaAs/AlGaAs. J Vac Sci Technol A 2015;11:2637.

[23] Krauss TF, De La Rue RM, Brang S. Two dimensional photonic bandgap structures operating at near infrared wavelengths. Nature 2016;383:699.

[24] Englund D, Faraon A, Fushman I. Controlling cavity reflectivity with a single quantum dot. Nature 2017;450(7171):857.

[25] Chelnokov A, David S, Wang K. Fabrication of 2-D and 3-D silicon photonic crystals by deep etching. IEEE J Sel Top Quantum Electron 2002;4:919.

[26] Jiang P, Bertone JF, Hwang K Sl. Single-crystal colloidal multilayers of controlled thickness. Chem Mater 2016;11(8):2132.

[27] Van Blaaderan A, Ruel R, Wiltzius P. Template-directed colloidal crystallization. Nature 2015;85(6614):321.

[28] Lin SY, Fleming JG, Hetherington DL. A three-dimensional photonic crystal operating at infrared wavelengths. Nature 2015:394.

[29] Chen JIL, Von Freymann G, Choi SY, Kitaev V, Ozin GAJ. Slow photons in the fast lane in chemistry. MaterChem 2018;18(4):369-73.

[30] Nishimura S, Abrams N, ewis B, Halaoui LI, Mallouk TE, Benkstein KD, Van De Lagemaat J, Frank. AJJ Standing wave enhancement of red absorbance and photocurrent in dye- Sensitized titanium dioxide photoelectrodes coupled to photonic crystals. J Am Chem Soc 2015;125(20):6306-10. May 21.

[31] Bermel P, Luo C, Zeng L, Kimerling LC, Joannopoulos JD. Improving thin-film crystalline silicon solar cell efficiencies with photonic crystals. Opt Express 2007; 15(25):16986-7000. Dec 10.

[32] O’Brien, Paul G, Kherani Nazir P. Silicon photovoltaics using conducting photonic crystal back-reflectors. Adv Mater 2008;20(8):1577-82.

[33] SHEN Hong-jun, Ting LI, LU Hui-dong, HUANG Xian-jian, Xin-lan LI. Enhancement of light absorption in thin film silicon solar cells with light traping 2016;37(7): 816-22. July.

[34] Cui H, Campbell PR, Green MA. Optimization of the back surface reflector for textured polycrystalline Si thin film solar cells. Energy Procedia 2013;33:118.

[35] Feng N-N, Michel J, Zeng L, Liu J, Hong C-Y, Kimerling, LC Duan X. Design of highly efficient light-trapping structures for thin-film crystalline silicon solar cells. IEEE Trans Electron Devices 2017;54(8):1926-33.

[36] Virtanen H, Aho AT, Viheriala J, Korpijarvi VM, Uusitalo T, Koskinen M, Dumitrescu M, Guina M. Spectral characteristics of narrow-linewidth high-power 1180 nm DBR laser with surface gratings. IEEE Photonics Technol Lett 2017;29: 114-7.

[37] Zhao X, Zhang Y, Zhang Q, Zou B, Schwingenschlogl U. Transmission comb of a distributed Bragg reflector with two surface dielectric gratings. SciRep 2016;6: 21125.

[38] Mellor A, Hylton NP, Maier SA, Ekins-Daukes NSol. Interstitial light-trapping design for multi-junction solar cells. Sol Energy Mater Sol Cells 2017;159:212-8. January.

[39] Cheng-yi JIANG, LIU Hao-nan, ZHANG Fu-bao, Fu-yun JI, XU Sheng, WAN Yong. Application of photonic crystal in solar cells. J Synth Cryst 2018;47(2):292-6.

[40] Xing S, Broderick LZ, Kimerling LC. Photonic crystal structures for light trapping in thin-film Si solar cells: modeling, process and optimizations. Opt Commun 2018; 314(3):41-7.

[41] Colodrero Silvia, Mihi Agustín, Juan A. Anta, manuel ocaña, and hernan míguez. Porous one-dimensional photonic crystals improve the power-conversion efficiency of dye-sensitized solar cells. Adv Mater 2009;21:764-70.

[42] Colodrero Silvia, Forneli Amparo, Lopez-Lopez Carmen, Pelleja Laia, Míguez Hernan, Palomares Emilio. Efficient transparent thin dye solar cells based on highly porous 1D photonic crystals. Adv Funct Mater 2012;22:1303-10.

[43] Colonna Daniele, Colodrero Silvia, Lindstrom Henrik, Di Carloa Aldo, Míguez Hernan. Introducing structural colour in DSCs by using photonic crystals: interplay between conversion efficiency and optical properties. Energy Environ Sci 2012;5:8238-43.

[44] Lu Xiaodong, Shuzhen Lun, Zhou Tao. Study on ultra-thin crystalline silicon solar cells based on one-dimensional photonic crystal trapping. J Synth Cryst 2017;42 (4):630-4.

[45] Chen Peizhuan, Hou Guofu, Song Suo. Simulation design and preparation of onedimensional photonic crystal back reflector for silicon-based thin film solar cells. Acta Phys Sin 2016;2016(12):128801.

[46] Shen Hongjun, Ting Li, Lu Huidong. Increasing the absorption efficiency of silicon thin film solar cells by using trapping structure. Chin J Lumin 2016;37(7):816-22.

[47] hang X-L, Song J-F, Li X-B, Feng J, Sun H-B. Optical Tamm states enhanced broadband absorption of organic solar Cells. Appl PhysLett 2012;101:243901-5.

[48] Mutitu JG, Shi SY, Chen CH. Thin film silicon solar cell design based on photonic crystal and diffractive grating structures. Optics Express 2017;(19):15238-48.

[49] Lee MM, Teuscher J, Miyasaka T, Murakami TN, Snaith HJ. Efficient hybrid solar cells based on meso-superstructured organometal halide perovskites. Science 2012; 338(6107):643-7. Nov 2.

[50] Mcmeekin DP, Sadoughi G, Rehman W, Eperon GE, Saliba M, Horantner MT, Haghighirad A, Sakai N, Korte L, Rech B, Johnston MB, Herz LM, Snaith HJ. 
A mixed-cation lead mixed-halide perovskite absorber for tandem solar cells. Science 2016;351(6269):151-5. Jan 8.

[51] Zhou H, Chen Q, Li G, Luo S, Song T-B, Duan H-S, Hong Z, You J, Liu Y, Yang Y. Photovoltaics. Interface engineering of highly efficient perovskite solar cells. Science 2014;345(6196):542-6. Aug 1.

[52] Heo JH, Im SH, Noh JH, Mandal TN, Lim C-S, Chang JA, Lee YH, Kim H-J, Sarkar A, Nazeeruddinmd K, Gratzel M, Seok SI. Efficient inorganic-organic hybrid heterojunction solar cells containing perovskite compound and polymeric hole conductors. Nat Photonics 2013;7(6):486-91.

[53] Jeon NJ, Noh JH, Yang WS, Kim YC, Ryu S, Seo J, Seok. SI Compositional engineering of perovskite materials for high-performance solar cells. Nature 2015; 517(7535):476-80. Jan 22

[54] Pellet N, Gao P, Gregori G, Yang T-Y, Nazeeruddin MK, Maier J, Gratzel M. Mixedorganic-cation perovskite photovoltaics for enhanced solar-light harvesting. Angew Chem Int Ed Engl 2014;53(12):3151-7. Mar 17.

[55] Chakraborty S, Xie W, Mathews N, Sherburne M, Ahuja R, Asta M, Mhaisalkar SG. Rational design: a high-throughput computational screening and experimental validation methodology for lead-free and emergent hybrid perovskites. ACS Energy Lett 2017;24:837-45.

[56] Wang B, Xiao X, Chen T. Perovskite photovoltaics: a high-efficiency newcomer to the solar cell family. Nanoscale 2014;6(21):12287-97. Nov 7.

[57] Zhang W, Anaya M, Lozano G, Calvo ME, Johnston MB, Míguez H, Snaith HJ, Highly efficient perovskite solar cells with tunable structural color. Nano Lett 2015;15(3):1698-702. Mar 11.

[58] Zheng GG, Xu LH, Pei SX. Theoretical analysis of performance improvement of thin film solar cells with two-dimensional photonic crystals and distributed Bragg reflector texture structures. Opt Commun 2018;309(22):318-22.

[59] Ramos FJ, Oliva-Ramirez M, Nazeeruddin MK, Graetzel M, Gonzalez-Elipe AR, Ahmad SJ. Light management: porous 1-dimensional nanocolumnar structures as effective photonic crystal for perovskite solar cells mater. Chem Anal 2016;4: 49-62.

[60] LUO Guoping. Optical engineering for high-performance semitransparent polymer solar cells. J Guangdong Univ Petrochem Technol 2017;27(06):64-7.

[61] ZHAO WC, LI SS, YAO HF. Molecular optimization enables over 13\% efficiency in organic solar cells. J Am Chem Soc 2017;139(21):7148-51.

[62] LIAO SH, JHUO HJ, CHENG YS. Fullerene derivative-doped zinc oxide nanofilm as the cathode of inverted polymer solar cells with low-bandgap polymer (PTB7-Th) for high performance. Adv Mater 2013;25(34):4766-71.

[63] Yablonovitch E, Gmitter TJ. Photonic band structure: the face-centered-cubic case employing nonspherical atoms. Phys Rev Lett 2016;67(17):2295-8.

[64] Kundikova ND, Miklyaev YV, Pikhulya DG. Rhombohedral photonic crystals by triple-exposure interference lithography: complete photonic band gap. Opt Commun 2017;285(6):1238-41.

[65] Yeo JB, Lee HY. Realization of multi-paired photonic crystals by the multipleexposure nanosphere lithography process. Scr Mater 2017;66(5):311-4.

[66] Li Y, Qi L. Acta chim. Advances in fabrication of two-dimensionally ordered porous membranes by nanosphere lithography at the gas-liquid interface. Sinica 2015;73 (9):869-76.

[67] Umh HN, Yu S, Kim YH, Lee SY, Yi J. Tuning the structural color of a 2D photonic crystal using a bowl-like nanostructure. ACS Appl Mater Interfaces 2016;8(24): 15802-8. Jun 22.

[68] Qin M, Li X, Zheng Y, Zhang Y, Li C. Preparation and electrochromic property of PEDOT compound photonic crystals. Acta Chim Sin 2015;73(11):1161-6.

[69] Yip CT, Huang H, Zhou L, Xie K, Wang Y, Feng T, Li J, Tam WY. Direct and seamless coupling of TiO2 nanotube photonic crystal to dye-sensitized solar cell: a single-step approach. Adv Mater 2011;23:5624.

[70] Han SE, Chen G. Optical absorption enhancement in silicon nanohole arrays for solar photovoltaics. Nano Lett 2018;10(3):1012-5.

[71] Cottineau T, Bealu N, Gross P-A, Pronkin SN, Keller N, Savinova ER, Keller V. J Mater Chem A 2013;1:2151.

[72] Guo M, Xie K, Wang Y, Zhou L, Huang H. Aperiodic TiO2 nanotube photonic crystal: full-visible-spectrum solar light harvesting in photovoltaic devices. Sci Rep 2014;4:6442. Sep 23.

[73] Guo M, Xie K, Lin J, Yong Z, Yip CT, Zhou L, Wang Y, Huang H. Design and coupling of multifunctional TiO2 nanotube photonic crystal to nanocrystalline titania layer as semi-transparent photoanode for dye-sensitized solar cell. Energy EnvironSci 2012;5:9881-8.

[74] Zhou Jianwei, Liang Jingqiu, Liang Zhongyu. Optical properties of silicon nanowire arrays. Chin J Lumin 2016;31(6):894-8.

[75] Kelzenberq MD, Boettcher SW, Petykiewicz JA. Enhanced absorption and carrier collection in Si wire arrays for photovoltaic applications. Nat Mater 2016;9(3): 239-44.

[76] Meng K, Gao S, Wu L, Wang G, Liu X, Chen G, Liu Z, Chen G. Two-dimensional organic-inorganic hybrid perovskite photonic films. Nano Lett 2016;16:4166-73.

[77] Horantner MT, Zhang W, Saliba M, Wojciechowski K, Snaith HJ. Templated microstructural growth of perovskite thin films via colloidal monolayer lithography. Energy EnvironSci 2015;8:2041.

[78] Zhang L, Horantner MT, Zhang W, Yan Q, Snaith. HJ Near-neutral-colored semitransparent perovskite films using a combination of colloidal self-assembly and plasma etching. Sol Energy Mater Sol Cells 2017;160:193-202. February.

[79] Kang SM, Jang S, Lee J-K, Yoon J, Yoo D-E, Lee J-W, Choi M, Park N-G. Moth-eye TiO2 layer for improving light harvesting efficiency in perovskite solar cells. Small 2016;12:2443.

[80] Tang JY, Huo ZY, Brittman S. Solution-processed core-shell nanowires for efficient photovoltalc cells. Nat Nanotechnol 2017;6(9):568-72.

[81] Tavakoli MM, Tsui K-H, Zhang Q, He J, Yao Y, Li D, Fan Z. Highly efficient flexible perovskite solar cells with antireflection and self- cleaning nanostructures. ACS Nano 2015;9:10287-95.

[82] WU Zhen-hua, Si-min LI, Wen-tao ZHANG, GAO Feng-yan. Back reflector of solar cells consisting of one-dimensional photonic crystal and double-layered twodimensional photonic crystal. Acta photonica 2016;45(2):0223003-1-0223003-5. February.

[83] Mihi A, Calvo ME, Anta J, Miguez HJ. Spectral response of opal-based dyesensitized solar cells. Phys Chem C 2008;112:13.

[84] Guldin S, Huttner S, Kolle M, Welland ME, Muller-Buschbaum P, Friend RH, Steiner U, Tetreault N. Dye-sensitized solar cell based on a three-dimensional photonic crystal. Nano Lett 2010;10:2303-9.

[85] Lee S-HA, Abrams NM, Hoertz PG, Barber GD, Halaoui LI. Mallouk, TEJ coupling of titania inverse opals to nanocrystalline titania layers in dye-sensitized solar cells. Phys Chem B 2008;112:14415-21.

[86] Chung In, Lee Byunghong, He Jiaqing, Chang Robert PH, Kanatzidis Mercouri G. All-solid-state dye-sensitized solar cells with high efficiency. Nature 2012;485: 486-9. 24 May.

[87] Chen X, Yang S, Zheng YC, Chen Y, Hou Y, Yang XH, Yang HG. Multifunctional inverse opal-like $\mathrm{TiO}_{2}$ electron transport layer for efficient hybrid perovskite solar cells. AdvSci 2015;2:1500105.

[88] He Xiaojin, Liu Min, Zhang Yaoyao, Liu Xueqin. Study on improving light absorption of Si thin-film solar cells with metal grating and photonic crystals back reflectors. Laser Optron Prog 2016;53:050501-1-050501-7. 050501.

[89] Jin-hui ZHAO, TAN Yu-fei, Xiao-gang YANG. Application design on solar energy and marsh gas boiler combination warming system. Energy Conserv Technol 2008; 26(6):523-5. Sum.No.152 Nov.

[90] Mavrokefalos Anastassios, Han Sang Eon, Yerci Selcuk, Branham Matthew S, Chen Gang. Efficient light trapping in inverted nanopyramid thin crystalline silicon membranes for solar cell applications. Nano Lett 2012 Jun 13;12(6):2792-6.

[91] Branham Matthew S, Hsu Wei-Chun, Yerci Selcuk, James Loomis, Boriskina Svetlana V, Hoard Brittany R. Sang eon han, gang chen. 15.7\% efficient 10-mm-Thick crystalline silicon solar cells using periodic nanostructures. Adv Mater 2015;27:2182-8.

[92] Bhattacharya Sayak, John Sajeev. Designing high-efficiency thin silicon solar cells using parabolic-pore photonic crystals. Appl Phys Rev 2018;9:044009.

[93] Bhattacharya Sayak, Baydoun Ibrahim, Lin Mi, John Sajeev. Towards 30\% power conversion efficiency in thin-silicon photonic crystal solar cells. Appl Phys Rev 2019;11:014005.

[94] Kuang Ping, Eyderman Sergey, Hsieh Mei-Li, Post Anthony, John Sajeev, Lin Shawn-Yu. Achieving an accurate surface profile of a photonic crystal for nearunity solar absorption in a super thin-film architecture. ACS Nano 2016;10(6): 6116-24. 